\title{
Observations from the NOAA P-3 aircraft during ATOMIC
}

\author{
Robert Pincus $^{1,2}$, Chris W. Fairall ${ }^{2}$, Adriana Bailey ${ }^{3}$, Haonan Chen ${ }^{4,2}$, Patrick Y. Chuang ${ }^{5}$, \\ Gijs de Boer $^{1,2}$, Graham Feingold ${ }^{6}$, Dean Henze ${ }^{7}$, Quinn T. Kalen ${ }^{8}$, Jan Kazil ${ }^{1,6}$, Mason Leandro ${ }^{5}$, \\ Ashley Lundry ${ }^{8}$, Ken Moran ${ }^{1,2}$, Dana A. Naeher ${ }^{8}$, David Noone ${ }^{7,9}$, Akshar J. Patel ${ }^{8}$, Sergio Pezoa ${ }^{2}$, \\ Ivan PopStefanija ${ }^{10}$, Elizabeth J. Thompson ${ }^{2}$, James Warnecke ${ }^{8}$, and Paquita Zuidema ${ }^{11}$ \\ ${ }^{1}$ Cooperative Institute for Research in Environmental Sciences, University of Colorado Boulder, \\ Boulder, Colorado, USA \\ ${ }^{2}$ NOAA Physical Sciences Laboratory, Boulder, Colorado, USA \\ ${ }^{3}$ National Center for Atmospheric Research, Boulder, Colorado, USA \\ ${ }^{4}$ Cooperative Institute for Research in the Atmosphere, Colorado State University, Fort Collins, Colorado, USA \\ ${ }^{5}$ Department of Earth and Planetary Sciences, University of California Santa Cruz, Santa Cruz, California, USA \\ ${ }^{6}$ NOAA Chemical Sciences Laboratory, Boulder, Colorado, USA \\ ${ }^{7}$ College of Earth, Ocean, and Atmospheric Science, Oregon State University, Corvallis, Oregon, USA \\ ${ }^{8}$ NOAA Aircraft Operations Center, Lakeland, Florida, USA \\ ${ }^{9}$ Department of Physics, University of Auckland, Auckland, New Zealand \\ ${ }^{10}$ ProSensing, Amherst, Massachusetts, USA \\ ${ }^{11}$ Rosenstiel School of Marine and Atmospheric Science, University of Miami, Miami, Florida, USA
}

Correspondence: Robert Pincus (robert.pincus@ colorado.edu)

Received: 13 January 2021 - Discussion started: 2 February 2021

Revised: 18 May 2021 - Accepted: 20 May 2021 - Published: 12 July 2021

\begin{abstract}
The Atlantic Tradewind Ocean-Atmosphere Mesoscale Interaction Campaign (ATOMIC), part of the larger experiment known as Elucidating the Role of Clouds-Circulation Coupling in Climate (EUREC ${ }^{4} \mathrm{~A}$ ), was held in the western Atlantic during the period 17 January-11 February 2020. This paper describes observations made during ATOMIC by the US National Oceanic and Atmospheric Administration's (NOAA) Lockheed WP-3D Orion research aircraft based on the island of Barbados. The aircraft obtained $95 \mathrm{~h}$ of observations over 11 flights, many of which were coordinated with the NOAA research ship R/V Ronald $H$. Brown and autonomous platforms deployed from the ship. Each flight contained a mixture of sampling strategies including high-altitude circles with frequent dropsonde deployment to characterize the large-scale environment, slow descents and ascents to measure the distribution of water vapor and its isotopic composition, stacked legs aimed at sampling the microphysical and thermodynamic state of the boundary layer, and offset straight flight legs for observing clouds and the ocean surface with remote sensing instruments and the thermal structure of the ocean with in situ sensors dropped from the plane. The characteristics of the in situ observations, expendable devices, and remote sensing instrumentation are described, as is the processing used in deriving estimates of physical quantities. Data archived at the National Center for Environmental Information include flight-level data such as aircraft navigation and basic thermodynamic information (NOAA Aircraft Operations Center and NOAA Physical Sciences Laboratory, 2020, https://doi.org/10.25921/7jf5-wv54); high-accuracy measurements of water vapor concentration from an isotope analyzer (National Center for Atmospheric Research, 2020, https://doi.org/10.25921/c5yx-7w29); in situ observations of aerosol, cloud, and precipitation size distributions (Leandro and Chuang, 2020, https://doi.org/10.25921/vwvq-5015); profiles of seawater temperature made with Airborne eXpendable BathyThermographs (AXBTs; NOAA Physical Sciences Laboratory, 2020a, https://doi.org/10.25921/pe39-sx75); radar reflectivity, Doppler velocity, and spectrum width from a nadir-looking W-band radar (NOAA Physical Sciences Laboratory, 2020c, https://doi.org/10.25921/n1hc-dc30); estimates of cloud presence, the cloud-top location, and the cloud-top radar reflectivity and temperature, along
\end{abstract}


with estimates of $10 \mathrm{~m}$ wind speed obtained from remote sensing instruments operating in the microwave and thermal infrared spectral regions (NOAA Physical Sciences Laboratory, 2020b, https://doi.org/10.25921/x9q59745); and ocean surface wave characteristics from a Wide Swath Radar Altimeter (Prosensing, Inc., 2020, https://doi.org/10.25921/qm06-qx04). Data are provided as netCDF files following Climate and Forecast conventions.

\section{Observing the atmosphere and ocean in the wintertime trades}

As part of the Atlantic Tradewind Ocean-Atmosphere Mesoscale Interaction Campaign (ATOMIC) the US National Oceanic and Atmospheric Administration (NOAA) operated a Lockheed WP-3D Orion research aircraft from the island of Barbados during the period 17 January-11 February 2020. The aircraft, known formally as N43RF and informally as "Miss Piggy", is one of two such aircraft in NOAA's hurricane hunter fleet. ATOMIC occurred as part of the field campaign EUREC ${ }^{4} \mathrm{~A}$ (Elucidating the Role of Clouds-Circulation Coupling in Climate; see Bony et al., 2017) focusing on relationships between oceanic shallow trade cumulus clouds and their environment, including the role of air-sea interactions.

ATOMIC included a cruise by the NOAA ship Ronald $H$. Brown (RHB) and deployments of autonomous aircraft and ocean vehicles. Measurements from the ocean platforms are described in Quinn et al. (2021). The main experimental area for EUREC ${ }^{4} \mathrm{~A}$ was just east of Barbados. Both the P-3 and the RHB primarily operated east of the EUREC ${ }^{4} \mathrm{~A}$ area (i.e., east of $57^{\circ} \mathrm{E}$ ), nominally upwind, within the "Tradewind Alley" (see Stevens et al., 2021) extending eastwards from the island of Barbados towards the Northwest Tropical Atlantic Station buoy near $15^{\circ} \mathrm{N}, 51^{\circ} \mathrm{W}$. Many of the $11 \mathrm{P}-3$ flights included excursions to the location of the RHB and sampling of atmospheric and oceanic conditions around the ship and other ocean vehicles. Because of its large size and long endurance (most flights were 8-9 h long) the P-3 was tasked with obtaining a wide array of observations including remote sensing of clouds and the ocean surface, in situ measurements within and below clouds and of isotopic composition throughout the lower troposphere, and the deployment of expendable profiling instruments in the atmosphere and ocean.

This paper describes observations made by the P-3 aircraft during ATOMIC. The next section describes the flights during which the measurements were obtained, including the flight plans designed to meet each objective. Instrumentation is described in Sect. 3. Data processing, including the calculation of derived quantities from one or more instruments, is detailed in Sect. 4, which also includes examples and select comparisons with measurements made by other platforms. Some measurements obtained from the P-3 are or will be included in cross-experiment datasets described elsewhere.

\section{Sampling strategy}

ATOMIC's goals, as the name implies, include illuminating the role of mesoscale circulations in the ocean and atmosphere as they influence the coupling between the two. As a result the flight strategies included a mix of four different kinds of segments.

1. High-altitude (nominally $24000 \mathrm{ft} / 7.5 \mathrm{~km}$ ) circles, nominally of $90 \mathrm{~km}$ radius, during which 12 dropsondes (see Sect. 3.2.1) were deployed to characterize the largescale vertical motion (Lenschow et al., 2007; Bony and Stevens, 2019). Many of the dropsonde circles were centered on the position of the Ronald H. Brown; others were in the location near Barbados that was routinely sampled by the German HALO aircraft. During daytime flights these were typically the first pattern flown.

2. Slow descents and ascents to sample thermodynamic profiles and the isotopic composition of water vapor (see Sect. 3.1.2). This pattern was usually flown at the end of the first dropsonde circle, descending from the circle level to $500 \mathrm{ft} / 150 \mathrm{~m}$ above the surface and then ascending to the flight level required for the next pattern.

3. In situ cloud sampling patterns, a series of vertically stacked straight and level legs at altitudes determined during flight. These altitudes were chosen to sample near the ocean surface, just below cloud base, one or more levels within the cloud layer, and just above it, allowing for the calculation of fluxes based on measurements of temperature, wind, and humidity (see Sect. 3.1.1 and 3.1.2) and cloud and aerosol size distributions (see Sect. 3.1.3). The location of these patterns was determined by the presence and characteristics of the clouds on the flight day.

4. Sets of horizontally offset long straight legs ("lawnmower patterns") designed to sample the co-variability of clouds and the ocean, emphasizing observations of ocean temperature profiles (Sect. 3.2.2) and the characteristics of ocean surface waves (Sect. 3.3.2). These patterns were flown at $9000-10000 \mathrm{ft} / 2.75-3 \mathrm{~km}$ so the aircraft could be depressurized to deploy Airborne eXpendable BathyThermographs (AXBTs); this altitude also provides good sensitivity for remote sensing of the ocean surface and clouds. These flight patterns were 
placed over regions of sea surface temperatures gradients and/or areas being sampled by autonomous ocean vehicles (surface drifters, wave gliders) deployed from the Ronald H. Brown.

Transits between Barbados and the daily operating area offered further opportunities for deploying dropsondes and AXBTs and for remote sensing. The P-3 flew 11 flights during ATOMIC for a total of $95 \mathrm{~h}$. The first eight flights took place during the day, with nominal takeoff times at 13:00 UTC (09:00 local time); the last three took place overnight, with takeoff times between 02:00-03:30 UTC (local times between 22:00 and 23:30 the previous day). Table 1 provides an overview of sampling strategies and other information for each flight. A plan (map) view of the flight tracks is shown in Fig. 1; altitudes are shown as a function of flight time in Fig. 2.

\section{Instrumentation and initial data processing}

Table 2 describes the instrumentation on and deployed from the P-3 during ATOMIC. The instrumentation was similar to that used during hurricane reconnaissance flights and other scientific missions with the exception of the water vapor isotope analyzer provided by the National Center for Atmospheric Research (see Sect. 3.1.2) and the nadir-looking W-band cloud radar provided by NOAA's Physical Sciences Laboratory (Sect. 3.3.1). Many of the basic in situ measurements are combined to provide derived quantities (e.g., wind speed, relative humidity) described in Sect. 4.

\subsection{In situ measurements}

\subsubsection{Flight level data}

Flight level data are recorded every second from the sensors installed on the P-3 via the Airborne Atmospheric Measurement and Profiling System (AAMPS). Some quantities are measured by multiple sensors; such values are denoted within files prepared by NOAA's Aircraft Operations Center (AOC) with a trailing integer for each independent measurement (e.g., TDM.1, TDM.2, and TDM.3 denote dew point temperature measurements from three independent sensors). Flight level data were post-processed and quality controlled by the flight directors (authors Quinn T. Kalen and Ashley Lundry during ATOMIC) after each flight, typically within a day during the campaign. Each sensor's data are verified to ensure that they represent sound meteorological conditions for that given instrument and then are marked as valid on the QC checklist included in the Mission Documents (available from https://seb.noaa.gov/pub/acdata/2020/ MET/ (last access: 11 June 2021) in directories labeled by flight date and the letter "I" to denote N43RF). In cases where there is more than one reliable sensor, one sensor is set as the reference, i.e., TDMref. The reference sensor is chosen to minimize data intermittency and maximize both comparisons to independent measurements (e.g., temperature may be compared to dropsondes) and self-consistency among measurements. The intent is to choose a single sensor which best represents the flight overall, even if this sensor might have periods of bad data (e.g., overshooting by the chilled-mirror dew point sensors) during the flight when other sensors might be more reliable. Additional parameters are derived (variable names end in ".d") and corrected (variable names end in ".c") from these data. AOC produces and distributes one netCDF file per flight. Both raw data and the AOC summary file are available for all flights from NOAA's National Center for Environmental Information (see https://www.ncei.noaa.gov/metadata/geoportal/ rest/metadata/item/gov.noaa.ncdc:C00581/html, last access: 11 June 2021, where files may be selected by project).

\subsubsection{Water vapor stable isotope analyzer}

During ATOMIC the P-3 was equipped with a flight-ready Picarro L2130-i water vapor isotopic analyzer which measured the concentration of water vapor and its isotopic composition at $5 \mathrm{~Hz}$ frequency. ATOMIC was the first flight campaign for this newly developed instrument although similar instruments have flown as part of previous airborne research missions (e.g., Sodemann et al., 2017; Herman et al., 2020). The isotope ratio measurements, which are part of a broad suite of such observations made during EUREC ${ }^{4} \mathrm{~A}$, are reported elsewhere; here we describe the instrument's fast and accurate measurements of water vapor concentration (i.e., mixing ratio).

While in flight, the isotopic analyzer drew in ambient air through a backwards-facing $0.25 \mathrm{in} . / 6.35 \mathrm{~mm}$ copper tube, centered within a National Center for Atmospheric Research HIAPER Modular Inlet (HIMIL). This ensured the selective sampling of water vapor (versus total water). Because mass but not volumetric flow was controlled through the copper tubing, the time delay ( $\tau$ in seconds) for air entering the HIMIL to reach the isotopic analyzer varied as a function of pressure and temperature. This delay may be approximated as $\tau=1.0748 p / T_{\text {set }}$, where $T_{\text {set }}$ is the set point $(\mathrm{K})$ of the heaters wrapping the copper tubing inside the aircraft cabin, $p$ is the ambient pressure $(\mathrm{hPa})$ recorded by the aircraft, and the constant (units of $\mathrm{s} \mathrm{K} \mathrm{hPa}^{-1}$ ) represents both the best approximation for the inner volume of the copper tube, including the $6 \mathrm{ft} / 183 \mathrm{~cm}$ inside the cabin and $1 \mathrm{ft} / 30.5 \mathrm{~cm}$ extending out through the HIMIL pylon, and the scale factor required to relate $T_{\text {set }}$ and $p$ to the standard conditions under which the volumetric flow rate of the isotopic analyzer is known. The tube inside the cabin was heated to $313.15 \mathrm{~K}$ during the first two flights and $321.15 \mathrm{~K}$ thereafter, resulting in a typical time delay of $3.4 \pm 0.3 \mathrm{~s}$ near the surface, which reduces by approximately $1 \mathrm{~s}$ for every $300 \mathrm{hPa}$ gained in altitude. Not all parameters in this equation are well constrained or fully representative of the exact sampling condi- 
Table 1. Flight sampling strategies employed on each flight by the P-3 during ATOMIC. Flight date is UTC and most flights were 8-9h long. Numbers in parentheses show the number of AXBTs for which valid data were obtained. "RHB" indicates that the R/V Ronald H. Brown was at the center of a dropsonde circle. Most AXBT patterns deployed 20 instruments. "Cloud" indicates the number of cloud patterns flown; each typically involved sampling at four or five altitudes. See also Table 3 of Quinn et al. (2021). Detailed reports from each flight are available at the EUREC ${ }^{4} \mathrm{~A}$ data portal (https://observations.ipsl.fr/aeris/eurec4a/, last access: 11 June 2021).

\begin{tabular}{llllll}
\hline Flight date & Circles & Dropsondes & AXBTs & Cloud & Notes \\
\hline 17 January & 1 & 23 & & 2 & RHB \\
19 January & 1 & 28 & $40(37)$ & & RHB; second isotope profile on return \\
23 January & 2 & 38 & $40(38)$ & & RHB (circle 1) \\
24 January & 2.5 & 16 & & 2 & Coordinated flight with EUREC ${ }^{4}$ A - no dropsondes during circles \\
31 January & 1 & 25 & & 2 & RHB \\
3 February & 1 & 22 & $21(21)$ & 1 & RHB; early return \\
4 February & & 31 & $20(20)$ & & \\
5 February & 1 & 29 & $20(19)$ & 3 & \\
9 February & 1 & 32 & $10(10)$ & 2 & Night flight, RHB \\
10 February & 1 & 32 & & 2 & Night flight, RHB \\
11 February & & 44 & $15(15)$ & & Night flight, RHB fly-by (no circle) \\
\hline
\end{tabular}

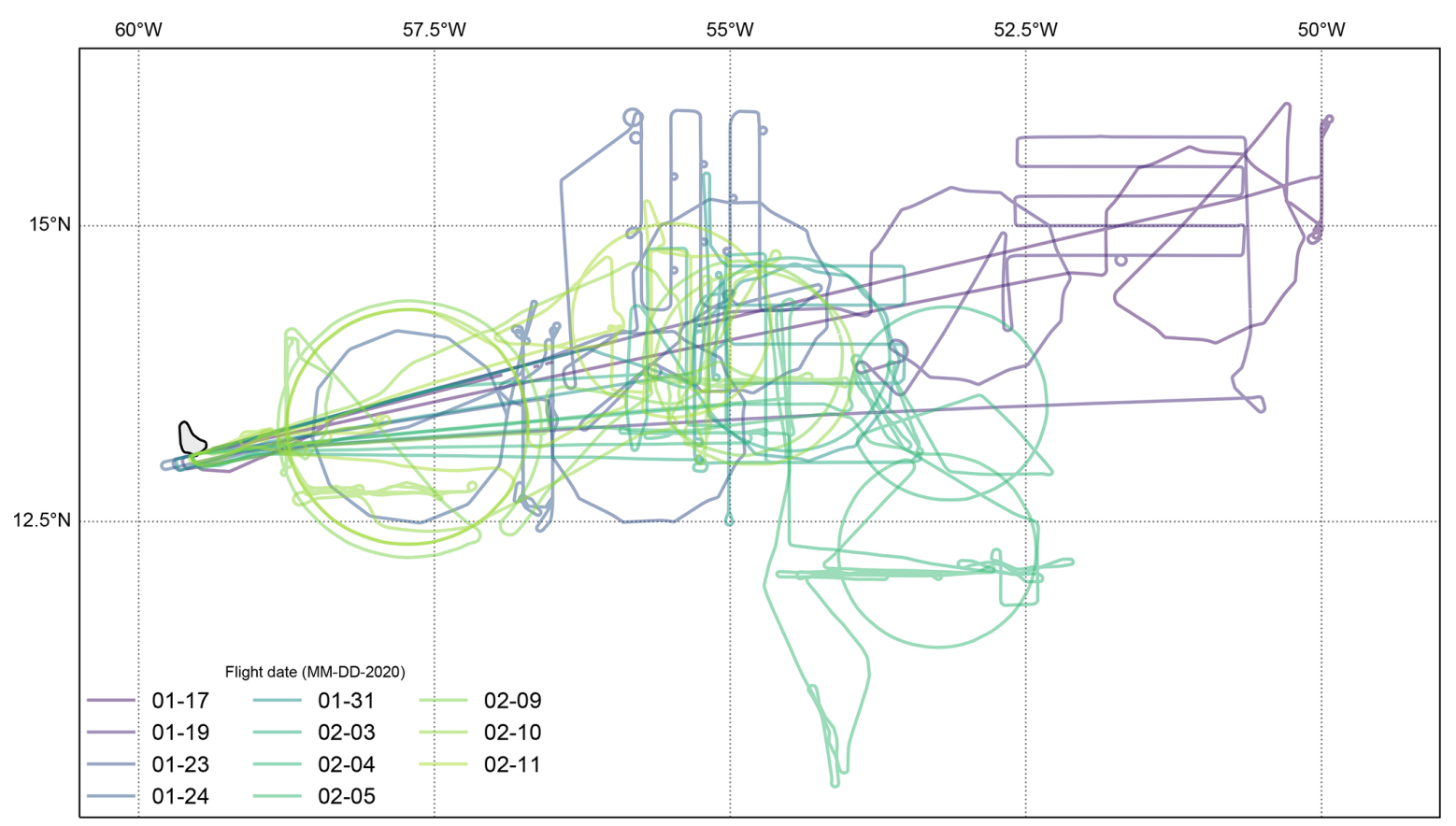

Figure 1. Flight tracks for the 11 flights made by the NOAA P-3 aircraft during ATOMIC on a map with the island of Barbados at left center. Most dropsondes were deployed from regular dodecagons during the first part of the experiment with short turns after each dropsonde providing an off-nadir look at the ocean surface useful for calibrating the W-band radar. A change in pilots midway through the experiment led to dropsondes being deployed from circular flight tracks starting on 31 January. AXBTs were deployed in lawnmower patterns (parallel offset legs) with small loops sometimes employed to lengthen the time between AXBT deployment to allow time for data acquisition given the device's slow fall speeds. Profiling and especially in situ cloud sampling legs sometimes deviated from straight paths to avoid hazardous weather. The color coding is drawn from a palette spanning the length of the experiment, so that days that are close in time have similar colors.

tions within the inlet; the uncertainty in $\tau$ may be roughly estimated by considering $p \pm 75 \mathrm{hPa}$.

Mixing of water vapor within the inlet system, and with molecules that have adsorbed to the copper tubing, also partially smooths high-frequency signals (Aemisegger et al.,
2012). These effects are, however, fairly small and consistent across flights. The aircraft hygrometer's time response, in contrast, is quite variable and depends on flight conditions, and the hygrometer is subject to both overshooting (e.g., when the measured signal surpasses the expected value fol- 
Table 2. Instrumentation aboard or deployed from the P-3 aircraft during the ATOMIC field campaign. Most instruments are the same or similar to those used during hurricane reconnaissance and other scientific missions, though the water vapor isotope analyzer and W-band radar were deployed specifically for this field campaign. See also Table A5 in Stevens et al. (2021).

\begin{tabular}{|c|c|c|}
\hline Instrument/sensor/package & Measurand & Notes \\
\hline \multicolumn{3}{|l|}{ In situ measurements } \\
\hline NovAtel DL-V3 GPS & Aircraft location, orientation & Primary (GPS.3; see Sect. 3.1.1) \\
\hline Northrop Grumman RINU-G & Aircraft heading & $\pm 0.02^{\circ}$ \\
\hline Rosemount 1281AF2B2BEP3 & Static pressure & $\pm 1.6 \mathrm{hPa}$ \\
\hline Rosemount 102AL & Air temperature & $\pm 0.1^{\circ} \mathrm{C}$ \\
\hline Buck Research 1011C & Dew point temperature & $\pm 0.5^{\circ} \mathrm{C}$; TDM. 1 (see Sect. 3.1.1) \\
\hline EdgeTech Vigilant & Dew point temperature & $\pm 0.5^{\circ} \mathrm{C} ;$ TDM. 2 (see Sect. 3.1.1) \\
\hline Vaisala PTB 220 & Cabin pressure & \\
\hline \multicolumn{3}{|c|}{ Water vapor isotope analyzer measurements } \\
\hline Picarro L2130-i & \multicolumn{2}{|l|}{ Water vapor concentration, isotopic composition } \\
\hline \multicolumn{3}{|c|}{ Microphysics measurements } \\
\hline Cloud and Aerosol Spectrometer & Particle size distribution & $0.5-50 \mu \mathrm{m}$ (starting 31 January 2020 ) \\
\hline Cloud Droplet Probe & Particle size distribution & $2-50 \mu \mathrm{m}$ (not functional during ATOMIC) \\
\hline Cloud Imaging Probe & Particle size distribution & $25-1550 \mu \mathrm{m}$ (starting 3 February 2020) \\
\hline Precipitation Imaging Probe & Particle size distribution & $100-6200 \mu \mathrm{m}$ (starting 4 February 2020) \\
\hline \multicolumn{3}{|l|}{ Expendables } \\
\hline Vaisala RD41 dropsondes & \multirow{2}{*}{\multicolumn{2}{|c|}{$\begin{array}{l}\text { Temperature, humidity, pressure, position vs. altitude } \\
\text { Seawater temperature vs. depth }\end{array}$}} \\
\hline Lockheed Martin Sippican AXBTs & & \\
\hline \multicolumn{3}{|l|}{ Remote sensors } \\
\hline \multirow[t]{2}{*}{ Heitronics KT19.85II } & \multirow{2}{*}{\multicolumn{2}{|c|}{$\begin{array}{l}\text { Infrared radiation } 9.6-11.5 \mu \mathrm{m} \\
\pm 0.5^{\circ} \mathrm{C} \text { plus } 0.7 \% \text { of the difference between target and housing temperatures }\end{array}$}} \\
\hline & & \\
\hline W-band radar & Intensity vs. Doppler shift & NOAA Physical Sciences Laboratory \\
\hline WSRA & $16 \mathrm{GHz}$ radar reflectivity & ProSensing \\
\hline SFMR & C-band brightness temperatures & ProSensing \\
\hline
\end{tabular}

lowing a rapid rise in environmental water vapor concentration) and ringing (i.e., rapid oscillations around the expected value) during rapid and large changes in water vapor concentration. This is illustrated in Fig. 3, which also highlights the hygrometer's much slower time response (as compared to the isotopic analyzer) in the low-humidity conditions found at the highest flight altitudes. Outside of these time periods, the agreement between the hygrometer and isotopic analyzer is quite good (lower panel). Given the more consistently accurate measurements of the isotopic analyzer during ATOMIC, we recommend its use in preference to the aircraft hygrometer for characterizing the thermodynamic state of the atmosphere.

\subsubsection{Microphysics}

A number of instruments for measuring aerosol and hydrometeor microphysical properties were aboard the P-3 during ATOMIC. All devices listed in Table 2 are standard instrumentation manufactured by Droplet Measurement Technologies. A Cloud and Aerosol Spectrometer (CAS; nominal diameter range 0.5 to $50 \mu \mathrm{m}$ ) and a Cloud Droplet Probe (CDP; nominal diameter range 2 to $50 \mu \mathrm{m}$ ) were deployed to measure aerosols and cloud suspended cloud particles. Precipitation drops were measured with a Cloud Imaging Probe (CIP; nominal diameter range $25 \mu \mathrm{m}$ to $1.55 \mathrm{~mm}$ ) and a Precipitation Imaging Probe (PIP; nominal diameter range $100 \mu \mathrm{m}$ to $6.2 \mathrm{~mm}$ ). All instruments were factory-calibrated immediately before the project.

Microphysics measurements were not made during all ATOMIC flights. The computer controlling the microphysical instruments failed on the first flight and took some time to replace so that no microphysical measurements were made during the first four flights. The CDP never functioned properly during the experiment, while the CIP did not function until the sixth flight on 3 February 2020 and the PIP until the seventh flight on 4 February 2020. Measurements are available from all other instruments for all remaining flights up to the end of the project. 


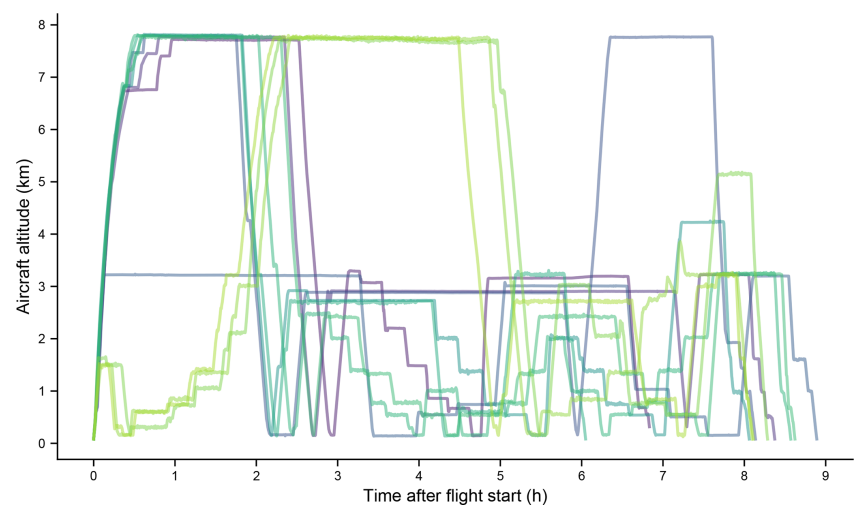

Figure 2. Flight altitude as a function of time after takeoff for the 11 flights by the NOAA P-3 aircraft during ATOMIC, using the same colors as Fig. 1. Sondes were dropped from $\sim 7.5 \mathrm{~km}$, with each circle taking roughly an hour; transits were frequently performed at this level to conserve fuel. Long intervals near $3 \mathrm{~km}$ were used to deploy AXBTs and/or characterize the ocean surface with remote sensing. Stepped legs indicate times devoted to in situ cloud sampling. On most flights the aircraft climbed quickly to roughly $7.5 \mathrm{~km}$, partly to deconflict with other aircraft participating in the experiment. On the three night flights, however, no other aircraft were operating at takeoff times and cloud sampling was performed first, nearer Barbados than on other flights.

\subsection{Expendable instrumentation}

\subsubsection{Dropsondes}

The P-3 released 320 Vaisala RD41 dropsondes during ATOMIC at the locations shown in Fig. 4. Most were released from $24000 \mathrm{ft} / 7.5 \mathrm{~km}$, though some were released from slightly lower altitudes during transits and others from 9000-10000 ft/2.75-3 km during cloud and AXBT flight patterns. The RD41 sensors measures pressure, temperature, and humidity as the package falls from the plane, slowed by a parachute (Hock and Franklin, 1999). A GPS package provides location from which wind direction and wind speed are calculated and reported in real time. Measurements are available from the aircraft flight level to the ocean surface. Dropsondes from the P-3 were processed in real time during flight and made available for assimilation over the Global Telecommunications System.

\subsubsection{AXBTs}

A total of 165 AXBT instruments (Bane and Sessions, 1984; Dinegar Boyd, 1987; Alappattu and Wang, 2015) were deployed from the P-3 over seven flights at locations shown in Fig. 5. Most were released at or near $9000 \mathrm{ft} / 2.75 \mathrm{~km}$. The AXBTs, manufactured by Lockheed Martin Sippican, collect ocean temperature as a function of time after launch. AXBTs normally begin transmitting data when the sensor enters the ocean. One file was produced for each AXBT sensor by removing any extraneous observations obtained be-

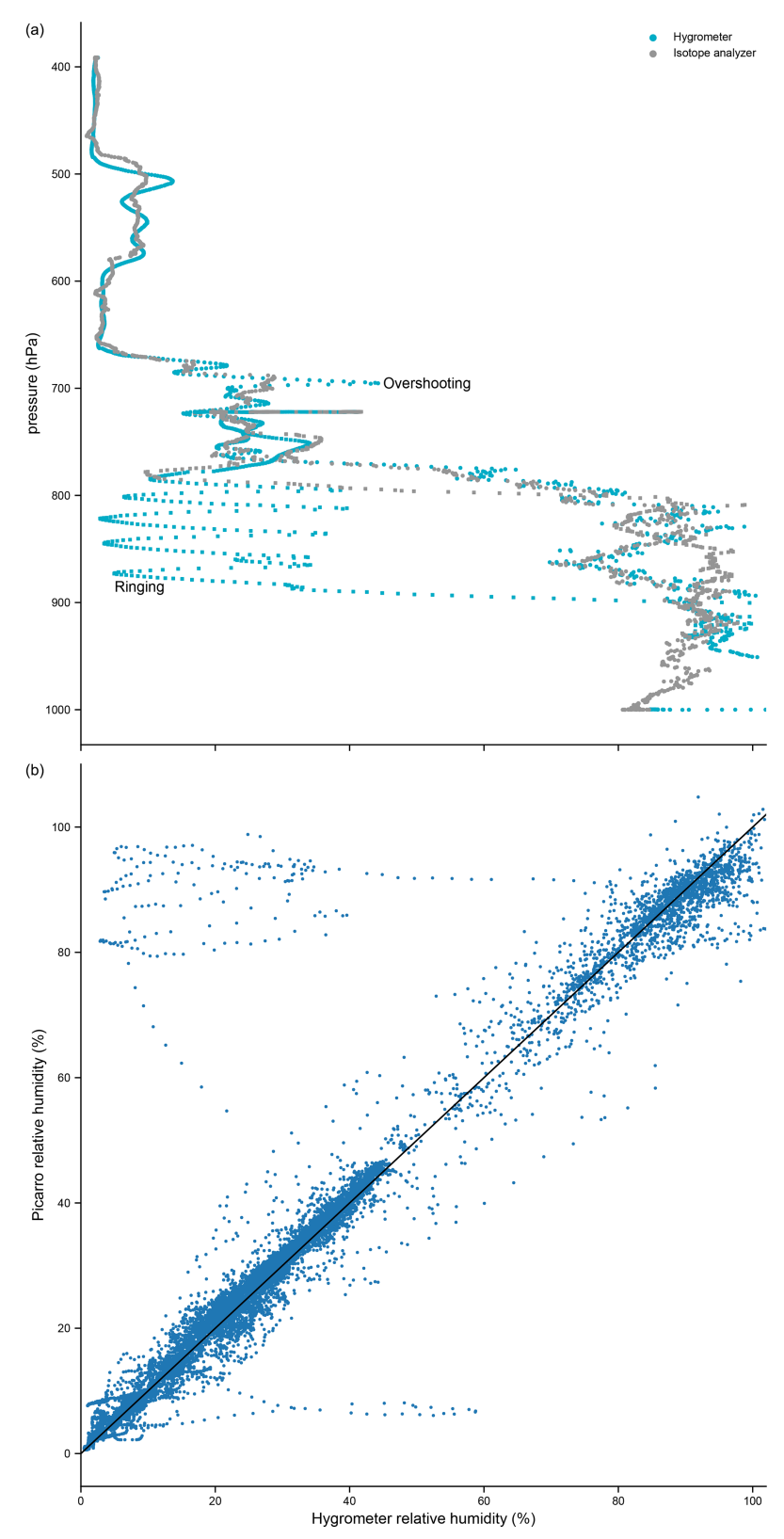

Figure 3. (a) Vertical profiles of relative humidity from the P3 hygrometer (teal) on 19 January 2020 show overshooting, ringing, and a slow time response under the low-humidity conditions found at the highest flight altitudes. These features are absent in the relative humidity profiles estimated from the water vapor isotopic analyzer (grey). Data in this panel are taken in two time windows (15:36:00 to 16:07:40 UTC, shown as circles, and 20:31:12 to 20:41:16 UTC, shown in squares) encompassing two separate slow profiles. (b) Relative humidity as measured by the two sensors over the entire flight. The black line indicates equality. There is good agreement between the two water vapor sensors when relative humidity exceeds $\sim 20 \%$ and when the hygrometer is not ringing or overshooting. 


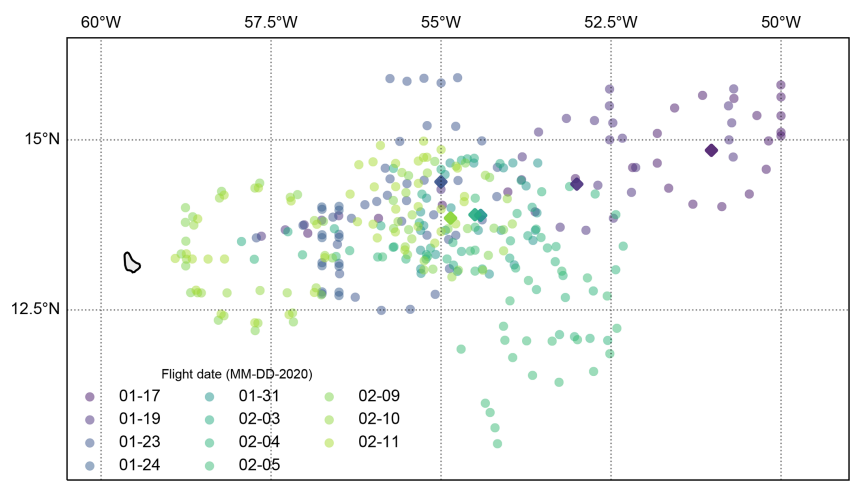

Figure 4. Location of dropsondes deployed during ATOMIC. Most circles (see Table 1) were centered on the position of the R/V Ronald H. Brown; the ship's position at the start of the circle is shown with a diamond.

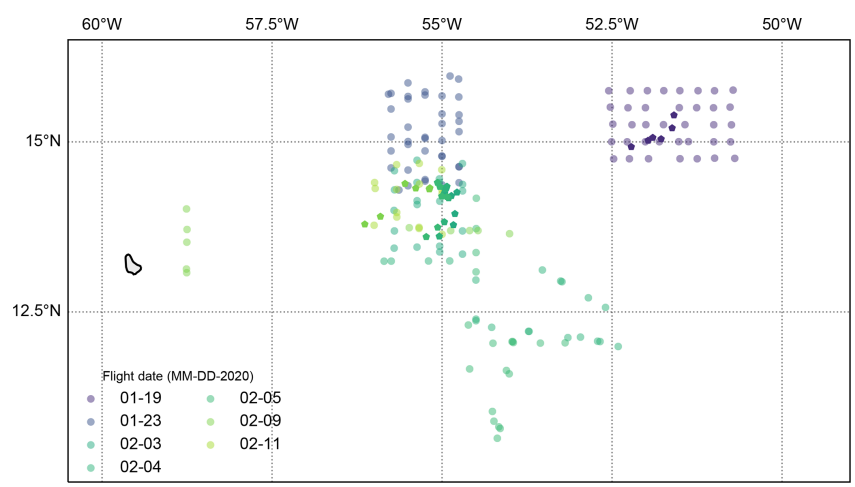

Figure 5. Location of AXBTs deployed during ATOMIC. Many were deployed in lawnmower patterns around the five drifting Surface Wave Instrument Float with Tracking (SWIFT) buoys described in Quinn et al. (2021); the positions of the buoys at the mid-point of the AXBT deployment is denoted with pentagons.

fore splashdown and then converting time to depth assuming a nominal in-water fall speed of $1.594 \mathrm{~m} \mathrm{~s}^{-1}$. Location is determined from the aircraft navigational information at the time the AXBT was released. A median filter was applied to remove most (but not all) spurious outliers in ocean water temperature.

\subsection{Remote sensing observations}

\subsubsection{Physical Sciences Laboratory W-band radar}

Remote sensing instrumentation on the P-3 during ATOMIC included the NOAA Physical Sciences Laboratory (PSL) Wband $(94 \mathrm{GHz})$ pulsed Doppler radar. The hardware and processing are described in Moran et al. (2012). It has been deployed from the surface (ships and land stations) looking up and from NOAA P-3 aircraft looking down. In ATOMIC the airborne radar was operated with $22030 \mathrm{~m}$ range gates with a dwell time of $0.5 \mathrm{~s}$. The minimum detectable reflectivity is $-36 \mathrm{dBZ}$ at a range of $1 \mathrm{~km}$, although accurate estimates of
Doppler properties require about $-30 \mathrm{dBZ}$ at $1 \mathrm{~km}$. A similar instrument was deployed on the RHB (Quinn et al., 2021).

Radar data were post-processed following Fairall et al. (2018). Standard processing produces vertical profiles of estimates of reflectivity, Doppler velocity, spectrum width, and cloud-free signal-to-noise ratio, converted to a uniform grid referenced to the sea surface rather than as distance from the aircraft. Reflectivity profiles are corrected for attenuation by atmospheric gases and precipitation. Absorption by water vapor and oxygen is calculated based on temperature, pressure, and relative humidity profiles measured by dropsondes using the model suggested by the ITU-R (2013). Attenuation by precipitation is estimated using inversions and relationships from Hitschfeld and Bordan (1954) following Iguchi and Meneghini (1994). Measured Doppler velocity is corrected for the pitch and roll components of aircraft motion. The vertical speed of the aircraft is calculated from flight level data (Sect. 3.1.1) and taken into account in the Doppler velocity correction especially during aircraft ascents and descents. An example from an hour of flight (18:00-19:00 UTC on 19 January) is shown in Fig. 6.

\subsubsection{Wide Swath Radar Altimeter}

The NOAA Wide Swath Radar Altimeter (WSRA; see Walsh et al., 2014; PopStefanija et al., 2020), developed and manufactured by ProSensing, Inc. of Amherst, MA, USA, is a digital beam-forming radar altimeter operating at $16 \mathrm{GHz}$ in the $\mathrm{Ku}$ band. It generates 80 narrow beams spread over $\pm 30^{\circ}$ to produce a topographic map of the sea surface waves and their backscattered power. These measurements allow for continuous reporting of directional ocean wave spectra and quantities derived from this including significant wave height, sea surface mean square slope, and the height, wavelength, and direction of propagation of primary and secondary wave fields. Rainfall rate is estimated from path-integrated attenuation (Walsh et al., 2014).

\subsubsection{Stepped Frequency Microwave Radiometer}

The Stepped Frequency Microwave Radiometer (SFMR) is a nadir-looking microwave radiometer also built by ProSensing. The instrument measures brightness temperatures of the ocean surface and intervening atmosphere at six C-band (4$7 \mathrm{GHz}$ ) frequencies. Surface wind speed and average columnar rain rate can be inferred from these brightness temperature values (Uhlhorn et al., 2007). The current implementation (Sapp et al., 2019) has its origins in prototypes developed by the Microwave Remote Sensing Laboratory at the University of Massachusetts and NOAA's Hurricane Research Division and deployed in 1980; the hardware and retrieval methods have been improved several times since. 
(a)
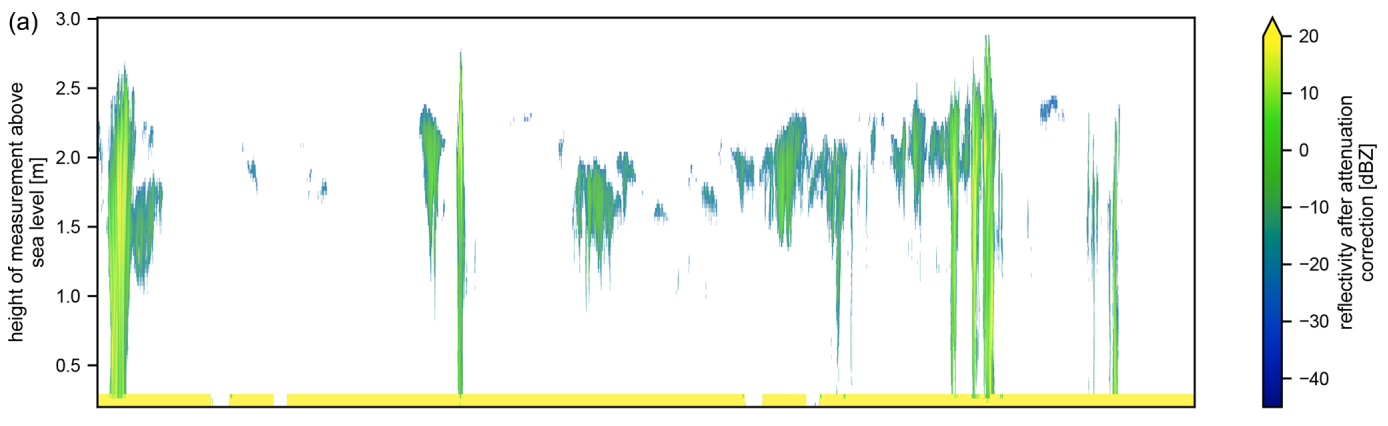

(b)
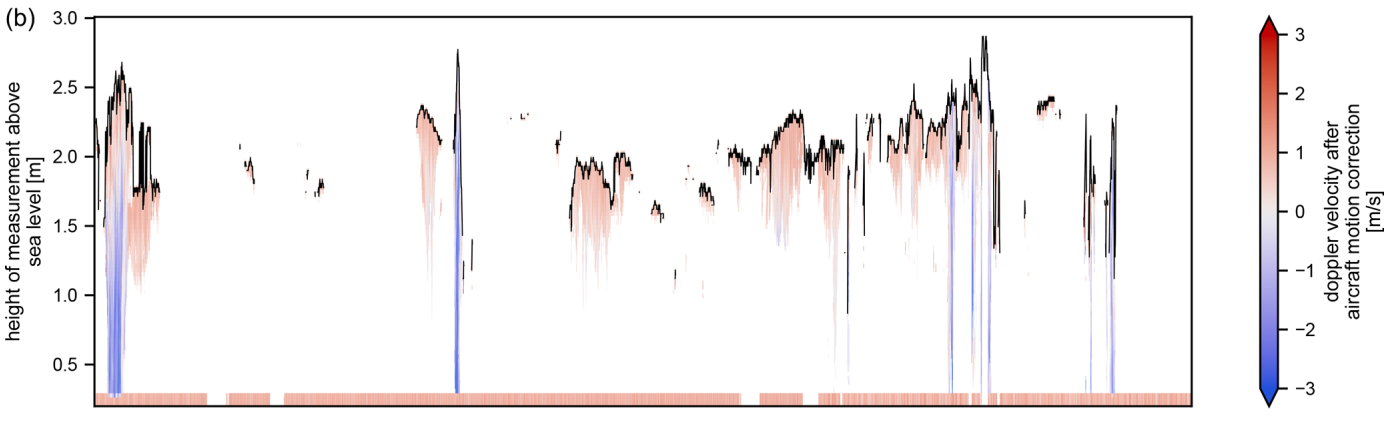

(c)

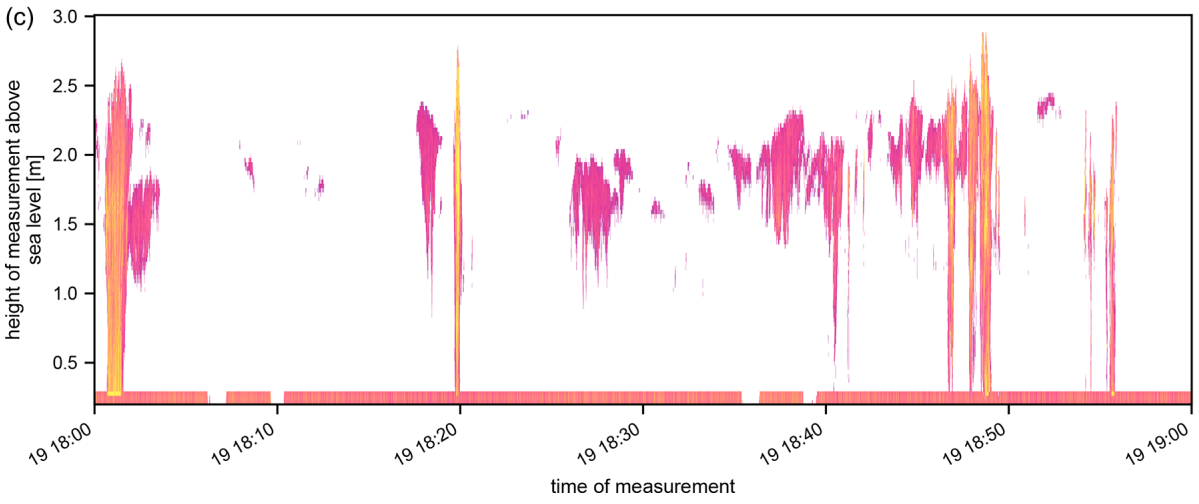

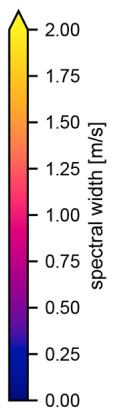

0.00

Figure 6. One example hour (18:00-19:00 UTC on 19 January 2020) of observations made by the W-band radar during ATOMIC. Panel (a) shows attenuation-corrected radar reflectivity $(\mathrm{dBZ})$; panel (b) shows the Doppler velocity after correction for aircraft motion $\left(\mathrm{ms}^{-1}\right)$; panel (c) shows the the width of the Doppler spectrum $\left(\mathrm{m} \mathrm{s}^{-1}\right)$. Observations with radar signal-to-noise ratio of less than $-10 \mathrm{~dB}$ have been removed for clarity. Clouds observed during this hour were relatively deep, frequently reaching $2.5-3 \mathrm{~km}$, with frequent periods of rain visible in the high-reflectivity, negative Doppler velocity (drops moving away from the aircraft, i.e., falling, in blue), and enhanced spectral width extending from near cloud top to the surface. During ATOMIC, clouds without precipitation typically have reflectivity less than $-25 \mathrm{dBZ}$; in this figure small precipitation drops (green colors in the reflectivity panel) are embedded in the clouds most of the time. The radar has sufficient sensitivity to see these weak returns out to about $2 \mathrm{~km}$ below the aircraft (about $1 \mathrm{~km}$ altitude). Doppler width is broadened by the aircraft flight speed, which adds a threshold of about $0.5 \mathrm{~m} \mathrm{~s}^{-1}$.

\subsubsection{Infrared radiometer}

The P-3 deployed three Heitronics KT19.85 passive infrared radiometers which measure radiation in the $9.6-11.5 \mu \mathrm{m}$ spectral range. One radiometer points horizontally out the port side of the plane; the others are zenith- nadir-looking. Measured radiation is converted to a brightness temperature. This system has a resolution of $0.1^{\circ} \mathrm{C}$ and an accuracy of $0.5^{\circ} \mathrm{C}$ plus $0.7 \%$ of the difference between the target and in- strument housing temperatures. The field of view is $0.5^{\circ}$ and the response time is approximately $0.5 \mathrm{~s}$.

\section{Post-processed and derived quantities}

Data obtained during the experiment have been postprocessed and a variety of derived quantities, as described in this section, have been produced. Data files are organized topically as described in Table 3 and explained more fully 
in this section. One file per day is provided for each of the entries in the table. All data are archived at the US National Center for Environmental Information.

\subsection{In situ data}

\subsubsection{Flight level data}

To simplify analysis and ease comparisons to other observations we have produced modestly reformatted data files containing a subset of flight level data. These files contain only the reference value of quantities measured by multiple sensors. Some variables are renamed for consistency with other platforms in ATOMIC and/or EUREC ${ }^{4} \mathrm{~A}$. Metadata are added or otherwise made consistent with conventions developed for the experiments. The dataset includes measurements of vertical velocity measurements made at $1 \mathrm{~Hz}$; these represent the only in situ measurements of turbulence made by the $\mathrm{P}-3$.

\subsubsection{Isotope analyzer}

Water vapor measurements from the isotopic analyzer are proportional to the ratio of the moles of water vapor to the moles of moist air (dry air plus water vapor) and are reported as a volume mixing ratio in parts per million volume (ppmv). These are provided alongside estimates of the mass mixing ratio - the ratio of the mass of water vapor to the mass of dry air - at both the analyzer's native time resolution of nominal $5 \mathrm{~Hz}$ frequency and at a reduced resolution of $1 \mathrm{~Hz}$ aligned with the P-3 aircraft data system through boxcar averaging. For convenience, estimates of relative humidity are also provided, obtained by multiplying the $1 \mathrm{~Hz}$ volume mixing ratios by the aircraft static (ambient) pressure measurements and dividing by the saturation vapor pressure, estimated from the aircraft ambient temperature following Hardy (1998).The files are aligned in time with the flight level data.

The isotopic analyzer's water vapor measurements have been corrected for a low bias of increasing magnitude at concentrations exceeding $10000 \mathrm{ppmv}$, identified using a LICOR 610 dew point generator. The uncertainty associated with this correction spans 26 to 29 ppmv for the humidity range 200 to 30000 ppmv but reduces to 12 ppmv upon averaging to $1 \mathrm{~Hz}$. The accuracy of volume mixing ratios below 200 ppmv is unverified.

\subsubsection{Microphysics}

Particle size distributions for microphysical instruments are processed at $1 \mathrm{~Hz}$ resolution for each day where data were available. The CAS and CDP are processed with standard codes available from the manufacturer (although, as noted in Sect. 3.1.3, the CDP did not produce useful data during ATOMIC and is therefore not included in the final archived product). The CIP and PIP provide quick-look data that are qualitatively useful, but accurate quantitative data require specialized processing of the individual particle images. The System for OAP Data Analysis version 2 (SODA-2, https: //github.com/abansemer/soda2, last access: 11 June 2021) is used to process the images to produce drop size distributions from both instruments. For the PIP, accurate sizing of particles up to $30 \mathrm{~mm}$ is possible in post-processing. However, particles larger than approximately $6 \mathrm{~mm}$ are typically ice particles; any such particles in the data should be ignored.

An aerosol size distribution is inferred from measurements that range from 0.5 to $2 \mu \mathrm{m}$ in size collected by the CAS. (Larger particles are included in the hydrometeor size distribution.) The division is motivated by size distributions observed during ATOMIC, which usually included two modes with the minimum between them typically close to $2 \mu \mathrm{m}$. Aerosol concentrations collected in cloud are higher than expected. This may be a result of cloud drop shattering at the CAS inlet, so these measurements should be treated with caution. We do not anticipate that we can correct this potential issue due to corruption of the CAS particle-by-particle files during the campaign.

Measurements collected by the CAS, CIP, and PIP at $1 \mathrm{~Hz}$ resolution are synthesized to generate a merged size distribution for hydrometeors ranging from 2 to $30 \mu \mathrm{m}$. The CAS, CIP, and PIP are used exclusively for hydrometeors in the size ranges of $2-50 \mu \mathrm{m}, 50-400 \mu \mathrm{m}$, and $1.8-30 \mathrm{~mm}$, respectively, although concentration of particles greater than $6 \mathrm{~mm}$ should not be considered reliable. For hydrometeors in the size range of $400 \mu \mathrm{m}-1.8 \mathrm{~mm}$, CIP observations are rebinned to the same size bins as the PIP and a sample volumeweighted average is computed. Figure 7 shows an example of the size distribution for each instrument along with the merged hydrometeor distribution. These are altitudeaveraged size distributions for one cloud module leg on 5 February 2020 from 19:51:48 to 20:07:18 UTC.

Quick-look videos are available for each cloud module. Each video is approximately $1 \mathrm{~min}$ in duration and displays aircraft altitude and the flight track superimposed on visible satellite imagery, along with second-by-second hydrometeor size distributions and scalar measures of this distribution (liquid water content, total number concentration, and Sauter mean or effective diameter) while in cloud, leg averages for these quantities, and the time spent in cloud for each cloud module leg. These videos are available alongside the numerical data.

\subsection{Expendables}

\subsubsection{Dropsondes}

Observations from the dropsondes (Sect. 3.2.1) deployed by the P-3 were processed alongside similar observations made from the high-altitude HALO aircraft as part of EUREC $^{4}$ to produce the Joint dropsonde-Observations of the Atmosphere in tropical North atlaNtic large-scale Environments (JOANNE) dataset described in George et al. 
Table 3. Data available from the P-3 during ATOMIC. Data are packaged as one file per type per flight day. Subsections within Sect. 4 describe the production of data beyond routine flight level data (Sect. 3.1.1) and the routinely processed radar observations (Sect. 3.3.1).

\begin{tabular}{llll}
\hline File type & Reference & Freq. & Data provided \\
\hline W-band radar & Sect. 3.3.1 & $2 \mathrm{~Hz}$ & radar reflectivity, Doppler velocity, spectrum width \\
\hline Flight level data & Sect. 4.1.1 & $1 \mathrm{~Hz}$ & $\begin{array}{l}\text { raw measurements as described in Table } 2 \\
\text { relative humidity } \\
\end{array}$ \\
& & $\begin{array}{l}\text { aircraft ground speed; true air speed; course over ground; true heading } \\
\text { wind speed and direction, wind velocity components }(u, v, w) \\
\end{array}$ \\
& & $10 \mathrm{~m}$ wind speed and rain rate from SFMR
\end{tabular}

\begin{tabular}{|c|c|c|c|}
\hline Isotope analyzer water vapor & Sect. 4.1 .2 & $1,5 \mathrm{~Hz}$ & Volume and mass mixing ratios and standard errors; relative humidity \\
\hline Particle size distributions & Sect. 4.1 .3 & $1 \mathrm{~Hz}$ & synthesized and per-instrument aerosol and cloud size distributions \\
\hline AXBTs & Sect. 4.2 .2 & & seawater temperature (profile) \\
\hline Remote sensing & Sect. 4.3.1 & $2 \mathrm{~Hz}$ & $\begin{array}{l}\text { radar and infrared cloud indexes } \\
\text { cloud-top altitude, wind speed, air temperature, radar reflectivity and Doppler velocity } \\
\text { infrared temperature at cloud-top } \\
\text { normalized radar cross section; sea surface mean square slope, rain rate (W-band) } \\
\text { corrected } 10-\mathrm{m} \text { wind from SFMR }\end{array}$ \\
\hline
\end{tabular}

\begin{tabular}{|c|c|c|c|}
\hline WSRA & Sect. 4.3 .2 & $0.02 \mathrm{~Hz}$ & $\begin{array}{l}\text { directional wave spectrum; peak spectral variance; rainfall rate } \\
\text { dominant and secondary wave height, direction, wavelength } \\
\text { sea surface mean square slope; significant wave height }\end{array}$ \\
\hline
\end{tabular}

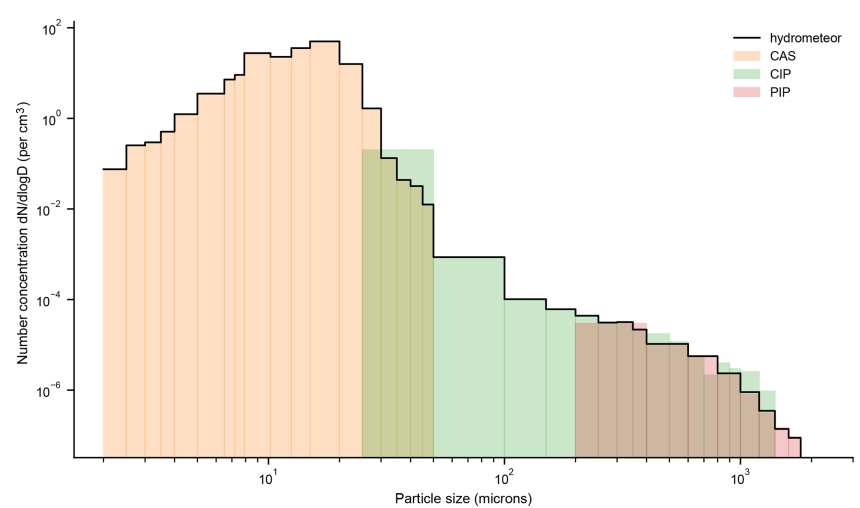

Figure 7. Size distributions for the CAS, CIP, and PIP (colored rectangles) along with the merged hydrometeor distribution (black line) synthesized from all three instruments. The figure demonstrate the re-binning described in the text. The figure shows data from a single cloud pattern leg on 5 February 2020 from 19:51:48 to 20:07:18 UTC.

(2021). JOANNE, which includes quality-controlled individual sounding profiles as well as calculations of circle-mean quantities, complements the compilation of radiosonde observations made during ATOMIC and EUREC ${ }^{4} \mathrm{~A}$ described in Stephan et al. (2021).

Figure 8 compares dropsonde profiles around the perimeter of the circle centered on the position of the Ronald $H$. Brown with a radiosonde launched from the ship. The P-3 entered the circle at 15:26 UTC and exited at 16:25, dropping sondes evenly throughout this window; the radiosonde was launched by the ship at 14:43 UTC to meet the synoptic deadline of 16:00 UTC. Despite this small temporal mismatch the thermal structures observed by the radiosondes and dropsondes are similar, with a small inversion near $5 \mathrm{~km}$ and a larger inversion near $2.5 \mathrm{~km}$, the height of which varies across and around the circle. Large jumps in the moisture field associated with these inversions exhibit similar vertical variability.

\subsubsection{AXBTs}

Following the processing of dropsonde data for JOANNE we have produced a single file containing all AXBTs profiles obtained during the ATOMIC, interpolated to a standard depth grid at $0.1 \mathrm{~m}$ vertical resolution. Figure 9 shows an example from the flight on 19 January 2020 in which 40 AXBTs were deployed in a lawnmower pattern bracketing five Surface Wave Instrument Float with Tracking (SWIFT; see Thomson, 2012) buoys deployed from the R/V Ronald $H$. Brown (see the upper right corner of Fig. 5). Figure 9 shows the ocean temperature as measured by the AXBTs between the surface and $150 \mathrm{~m}$ depth, with a near-isothermal mixed layer extending tens of meters and the cooler ocean below 60-80 $\mathrm{m}$. The inset compares the temperature in the first $3 \mathrm{~m}$ with measurements made by the SWIFT buoys (see Quinn et al., 2021), nominally at $0.3-0.5 \mathrm{~m}$ depth depending on the particular buoy. Upper ocean temperatures measured by the AXBTs span $1 \mathrm{~K}$; the range across the SWIFTs, which were more geographically confined, is about a fifth of this. Submesoscale and mesoscale eddies, fronts, and filaments in the ocean contribute to localized temperature gradients within this region (see also Fig. 4 in Quinn et al., 2021). 

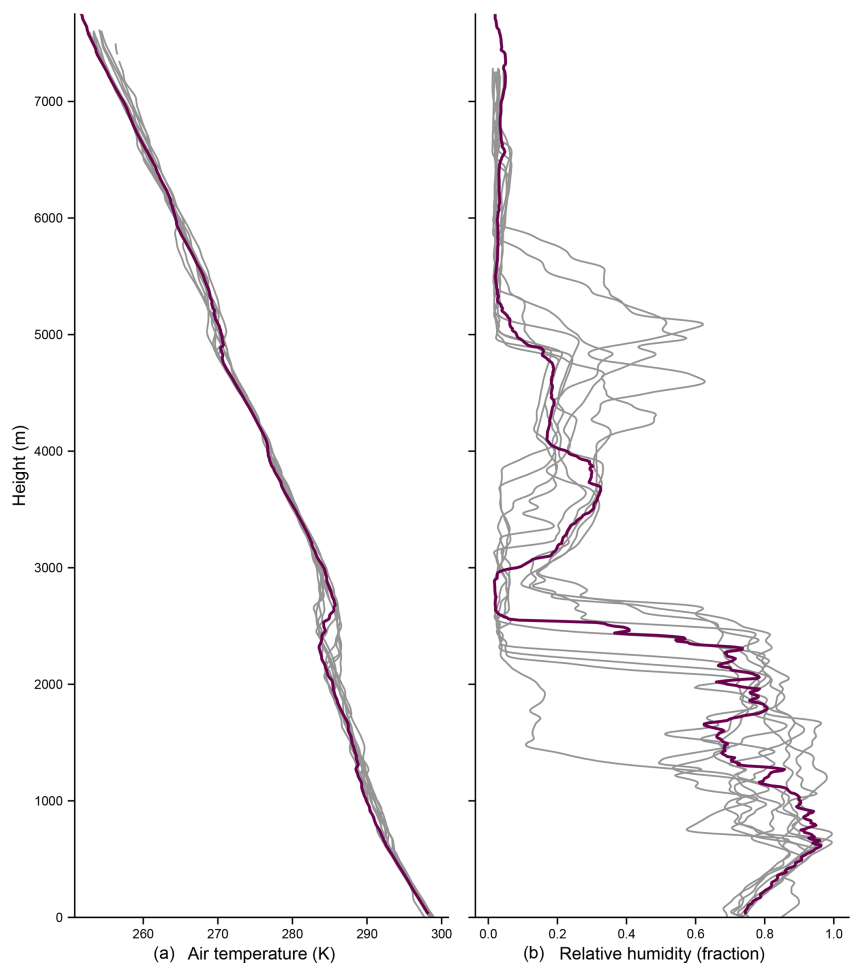

Figure 8. Profiles of air temperature (a) and relative humidity with respect to liquid (b) as obtained by dropsondes deployed from the P-3 (grey) and a radiosonde launched from the Ronald H. Brown (dark red). Dropsonde data are obtained from JOANNE (see text); radiosonde observations are obtained from the dataset described in Stephan et al. (2021). One of the 12 sondes shows much lower humidity from $1.5-2.5 \mathrm{~km}$ than do the others; we are assessing all the dropsonde circles to understand if this is common or an instrumental artifact.

\subsection{Remote sensing}

\subsubsection{W-band radar and infrared radiometer: clouds, precipitation, and sea state}

We use observations from the W-band radar (Sect. 3.3.1) to estimate ocean surface parameters and, in combination with measurements from the downward-looking infrared radiometer (Sect. 3.3.4), to provide estimates of cloud properties. Both sets of parameters are distributed with navigation data interpolated to the $2 \mathrm{~Hz}$ radar time base. The file also contains values of the $10 \mathrm{~m}$ SFMR wind speed, both as reported by the instrument and as corrected via linear regression using dropsonde winds as the reference.

Estimates of sea state and precipitation rate make use of the strong reflection of the $\mathrm{W}$-band radar from the ocean surface. Following Fairall et al. (2018) we report the measured normalized radar cross section $\mathrm{NRCS}_{\mathrm{m}}$ based on the

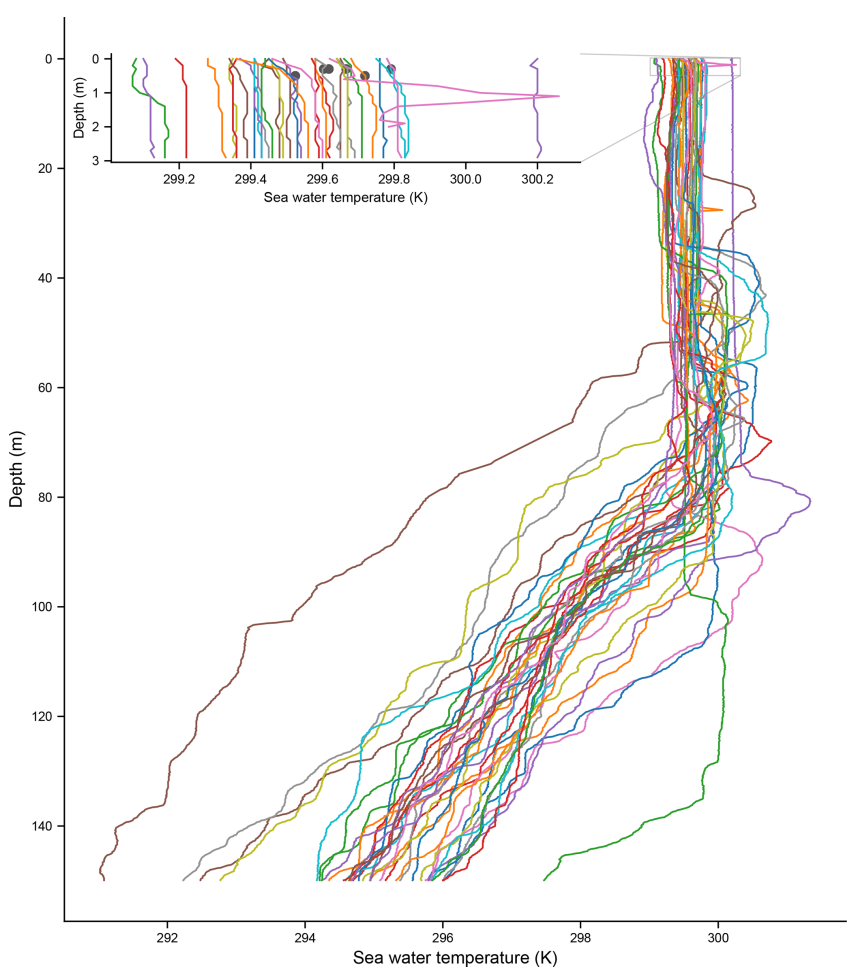

Figure 9. Ocean temperature profiles as measured by AXBTs deployed from the P-3 on 19 January 2020. Data are shown between the near-surface and a depth of $150 \mathrm{~m}$, though the actual profiles extend to nearly $1000 \mathrm{~m}$ depth. The inset shows ocean temperatures in the first few meters along with measurements from the five SWIFT buoys (see Quinn et al., 2021) surrounded by the AXBT deployments. Three of the 40 AXBTs deployed did not provide valid data.

observed reflectivity factor of the ocean surface $\mathrm{dBZ}_{e}(0)$

$$
\begin{aligned}
\mathrm{NRCS}_{\mathrm{m}}= & \mathrm{dBZ}_{e}(0)+10 \log _{10}\left(\pi^{5}\left|K^{2}\right| \delta R / \lambda^{4}\right) \\
& -180+\mathrm{dBZ}_{\mathrm{attn}} .
\end{aligned}
$$

For the PSL W-band with its $30 \mathrm{~m}$ range resolution, the second term on the right-hand side of Eq. (1) is 137.9, while the correction factor for attenuation by water vapor and oxygen is roughly $\mathrm{dBZ}_{\mathrm{attn}}=4$ for typical ATOMIC conditions with the aircraft at $3 \mathrm{~km}$ altitude. During ATOMIC the signal from the surface was strong enough to cause some saturation of the receiver, reducing the sensitivity the nearer the aircraft was to the surface. Values of $\mathrm{NRCS}_{\mathrm{m}}$ have been further adjusted for this effect as a function of pressure; the correction is small for altitudes higher than $5 \mathrm{~km}$ but is as large as $8 \mathrm{~dB}$ at $1 \mathrm{~km}$ above sea level.

The back-scattered radar return from the ocean surface $\sigma$ depends on both wind speed and viewing angle $\theta$; this dependence can be exploited to estimate the mean square slope $\overline{s^{2}}$ of surface waves (satellite-borne radar scatterometer wind estimates exploit the same physics). The dependence is usu- 


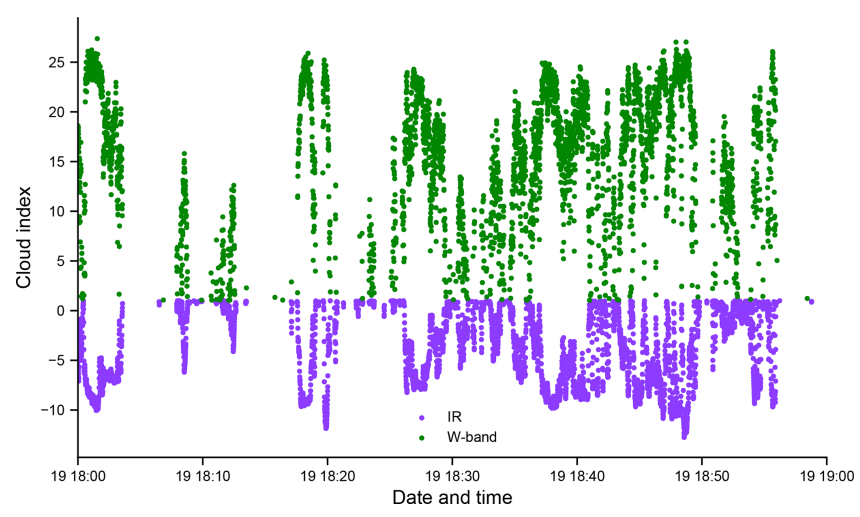

Figure 10. Cloud indexes based on radar ( $C^{\text {radar }}$, green) and infrared radiometer ( $C^{\mathrm{IR}}$, purple) measurements for the period 18:0019:00 UTC on 19 January (cf. Fig. 6). Cloud is indicated by values of $C^{\text {radar }}>0$ and $C^{\mathrm{IR}}<0$. Absolute values less than one have been removed for clarity. The two indexes are quite consistent with one another because clouds, when present, are typically opaque enough to be easily detectable in both infrared and microwave measurements.

ally represented (Walsh et al., 1998; Li et al., 2005) as

$\sigma=\frac{\Gamma^{2}}{\overline{s^{2}} \cdot \cos ^{4} \theta} \exp \left(\frac{-\tan ^{2} \theta}{\overline{s^{2}}}\right)$,

where $\Gamma^{2}$ is a wavelength-dependent constant with value 0.32 at $\mathrm{W}$-band radar frequencies and the theoretical or calculated normalized radar cross section $\operatorname{NRCS}_{\mathrm{c}}=10 \log _{10}(\sigma)$. We solve Eq. (2) for $\overline{s^{2}}$, using observations made a nadirviewing angles $(\theta=0)$ and assuming $\mathrm{NRCS}_{\mathrm{c}}=\mathrm{NRCS}_{\mathrm{m}}$. These estimates rely on radar calibration.

Following Fairall et al. (2018) the precipitation rate is determined from the W-band radar using the vertical gradient of radar reflectivity during light rain and the path-integrated attenuation during the infrequent heavy rain observed during ATOMIC.

Clouds are detectable in both the radar reflectivity profile and the observed infrared brightness temperature. A radar cloud presence index $C^{\text {radar }}$ is determined by examining the maximum signal-to-noise ratio (SNR) within each radar column (excluding the surface return). The clear-sky signal-tonoise level of the radar is nominally $-20 \mathrm{~dB}$, but a value of about -15 is needed to ensure a valid cloud return. We define the index as $C^{\text {radar }}=\max (\mathrm{SNR})+14$ so that values of $C^{\text {radar }}>0$ indicate clouds. When clouds are detected cloudtop height $z_{\text {ct }}$ is estimated as the level closest to the aircraft at which SNR $>14$. Cloud-top height diagnosed in this way is shown in the middle panel of Fig. 6. We report the radar reflectivity factor and Doppler velocity at this height as well as the wind speed $w\left(z_{\mathrm{ct}}\right)$ and air temperature $T\left(z_{\mathrm{ct}}\right.$ as determined from daily-mean in situ aircraft profiles (not dropsondes).

An infrared cloud presence index $C^{\mathrm{IR}}$ is produced based on the observed nadir-looking brightness temperature $T^{\mathrm{IR}}(p)$

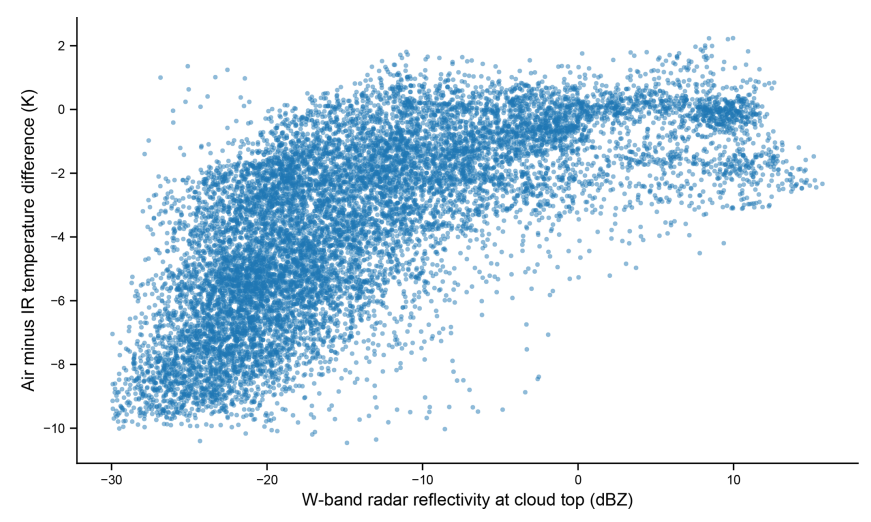

Figure 11. Difference between air temperature at cloud top $T_{\mathrm{ct}}^{\mathrm{air}}$ and the observed IR temperature $T_{\mathrm{ct}}^{\mathrm{IR}}$ as a function of W-band radar reflectivity at cloud top for the entire flight made on 19 January 2020. The height of the cloud top is determined as the closest position to the observing aircraft at which the radar signal-to-noise ratio exceeds $14 \mathrm{~dB}$; air temperature as a function of height is determined from in situ samples made by the aircraft. Temperature differences near zero indicate that the clouds are optically thick in the infrared.

made at aircraft operating pressure $p$. We compare clearsky measurements of $T^{\mathrm{IR}}(p)$ to the near-surface radiometric temperature, determined from the time mean of infrared radiometer measurements during flight legs at $150 \mathrm{~m}$, to develop a correction term $\Delta T^{\mathrm{IR}}\left(p-p^{\prime}\right)=\mathrm{SST}-T_{\text {clear }}^{\mathrm{IR}}\left(p-p_{\mathrm{sfc}}\right)$ as a quadratic function of $p-p^{\prime}$. The infrared cloud index $C^{\mathrm{IR}}$ is defined as the difference between the observed infrared temperature and the value expected in the absence of clouds, i.e., $C^{\mathrm{IR}}=T^{\mathrm{IR}}(p)-\left(\mathrm{SST}-\Delta T^{\mathrm{IR}}\left(p-p_{\mathrm{sfc}}\right)\right)$, so that values of $C^{\mathrm{IR}}<0$ indicate clouds.

The two cloud indexes complement one another. The Wband radar sensitivity is limited, and, particularly when the aircraft was transiting or dropping sondes at $7.5 \mathrm{~km}$ altitude (about a quarter of the total flight time), many clouds near the surface were beyond the viewing range of the radar and are therefore not detectable in the radar return. For these flight legs the IR cloud index is likely a better indicator of cloudiness. When the aircraft is at or below about $3 \mathrm{~km}$, the radar is very sensitive to clouds and likely detects all clouds with radar reflectivity factor $Z_{e}>-35 \mathrm{dBZ}$. Under these circumstances the radar and infrared cloud indexes are quite consistent with one another, as shown for an example hour of observations on 19 January 2020 in Fig. 10.

When cloud-top height $z_{\mathrm{ct}}$ is available from the radar we use this information to identify cloud-top pressure $p_{\mathrm{ct}}$ and, from aircraft soundings, the temperature at that pressure $T_{\mathrm{ct}}^{\mathrm{air}}$. This can be compared to IR cloud-top temperature corrected for the intervening atmosphere $T_{\mathrm{ct}}^{\mathrm{IR}}=T^{\mathrm{IR}}(p)+\Delta T^{\mathrm{IR}}(p-$ $\left.p_{\mathrm{ct}}\right)$. Values of $T_{\mathrm{ct}}^{\mathrm{IR}} \approx T_{\mathrm{ct}}^{\mathrm{air}}$ indicate that optically thick clouds fill the infrared radiometer's field of view. In Fig. 11 we show the difference in cloud-top air temperature and apparent IR cloud-top temperature as a function of $\mathrm{W}$-band reflectivity 


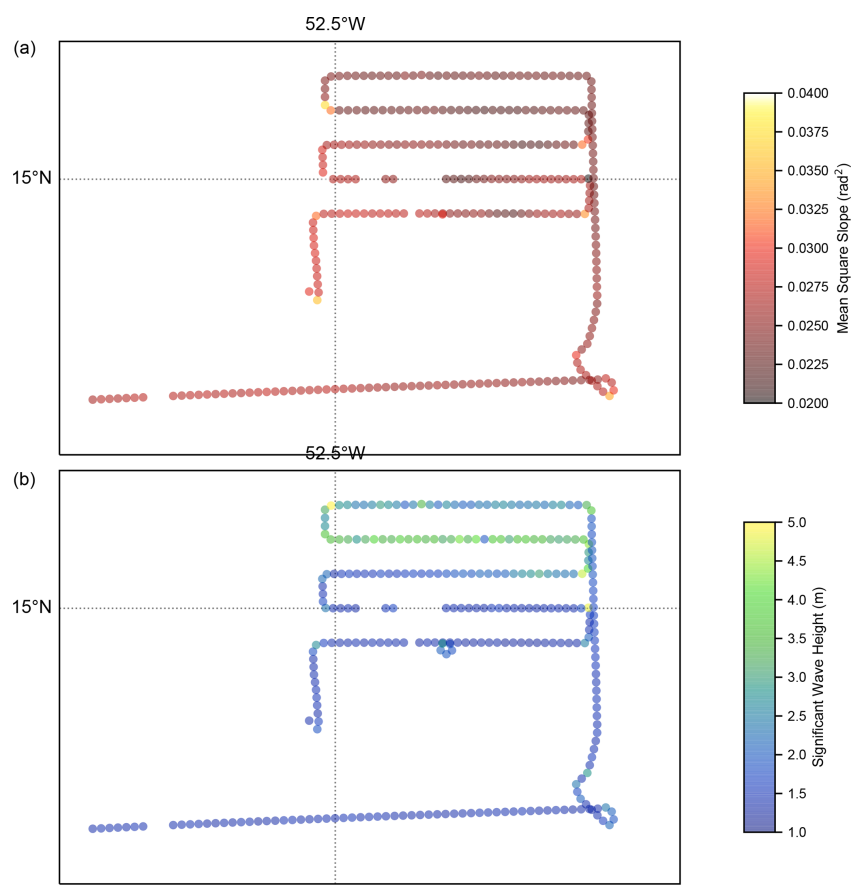

Figure 12. Observations of surface wave state from the Wide Swath Radar Altimeter (WSRA) during the P-3 flight of 19 January 2020. (a) Mean square slope $\left(\operatorname{rad}^{2}\right)$. (b) Significant wave height (m).

from 19 January. Values of $T_{\mathrm{ct}}^{\mathrm{IR}}-T_{\mathrm{ct}}^{\text {air }}$ less than zero indicate the cloud is optically thin or does not completely fill the $0.5 \mathrm{~s}$ sample and some radiation from the warm sea surface is adding to the measured IR.

\subsubsection{WSRA: sea state and rain rate information}

ProSensing Inc. processes raw data from the Wide Swath Radar Altimeter (WSRA; see Sect. 3.3.2) to produce information about the wave state of the ocean surface. Most observations - including the power spectrum of surface waves as a function of wavenumber in the north-south and east-west directions; the direction, height, and wavelength of the two most dominant waves; peak spectral variance; and the significant wave height - are reported every $50 \mathrm{~s}$. A plan view of observations obtained on 19 January 2020 is shown in Fig. 12. Rainfall rate and surface wave $\overline{s^{2}}$ are reported every $10 \mathrm{~s}$. The latter is computed from the decrease in the intensity of the return with scan angle following Eq. (2), so, unlike estimates of $\overline{s^{2}}$ from the W-band radar, estimates from the WSRA do not depend on absolute calibration.

Files with these estimates also contain bookkeeping information (processing parameters and ancillary data) such as aircraft navigation and orientation and other fields that may be useful. In particular, the directional wave spectra calculated from data collected with WSRA inherently contain a $180^{\circ}$ ambiguity of the wave propagation which can generally be eliminated using a rough estimate of a predicted domi- nant ocean wave direction at the location of the observation point. During ATOMIC the prevailing wind direction (typically ENE to WSW) was used as the predicted ocean wave direction for the entire duration of each flight mission. For completeness WSRA files contain directional wave spectra with and without this ambiguity removed.

During ATOMIC the aircraft operated in a number of modes that were unfavorable for collecting WSRA data. Data should not be used if the aircraft altitude is less than $500 \mathrm{~m}$ or greater than $4000 \mathrm{~m}$, or when the aircraft's pitch or roll exceeds $\pm 3^{\circ}$. We also recommend using observations only when the peak spectral value is in the range 0.0002 $0.006 \mathrm{~m}^{2}$.

\section{Code and data availability}

Data have been reformatted into netCDF files following CF (Climate and Forecast) conventions (https://cfconventions. org, last access: 11 June 2021), which provide for units and standard names for variables, a uniform handling of time, and other metadata intended to promote interoperability and interpretability. The files also contain some provenance information following guidance developed for $\mathrm{EUREC}^{4} \mathrm{~A}$. Isotope ratios from the isotope analyzer aboard the P-3 (Sect. 3.1.2) will be described as part of a paper describing the aircraft-, ship-, and ground-based observations made during the experiments.

Data have been archived at NOAA's National Center for Environmental Information as detailed in Table 4. This represents the version of record. The data are also replicated at the French AERIS data center alongside the wide array of other data from the EUREC ${ }^{4} \mathrm{~A}$ experiment $(\mathrm{OPeN}$ DAP access via https://observations.ipsl.fr/thredds/catalog/ EUREC4A/catalog.html, last access: 11 June 2021).

\section{Conclusions}

Measurements from the P-3 during ATOMIC took place in the context of marine measurements in the remote ocean (Quinn et al., 2021) and autonomous airborne measurements made from the island of Barbados (de Boer et al., 2021), all aimed at understanding how mesoscale structures in the atmosphere and ocean affect the coupling between the two components of the earth system. The measurements exist in the wider context of EUREC4A (Stevens et al., 2021) and, in aggregate, provide an unprecedented look at the tropical atmosphere, the shallow clouds embedded in it, and the ocean as a coupled system.

Author contributions. CWF was the principal investigator for the aircraft during the ATOMIC mission. CWF, RP, JK, GF, and $\mathrm{PZ}$ each acted as a flight scientist for one or more research flights. $\mathrm{AB}$ and $\mathrm{DH}$ were responsible for operating the Picarro instrument. $\mathrm{ML}$ and PJC produced the microphysical size distributions. IP ob- 
Table 4. Data described in this paper and archived at NOAA's National Center for Environmental Information. The contents of each file are summarized in Table 3; document object identifiers (DOIs) point to netCDF files following Climate and Forecast conventions.

\begin{tabular}{lll}
\hline File type & DOI & Reference \\
\hline Flight level data & https://doi.org/10.25921/7jf5-wv54 & $\begin{array}{l}\text { NOAA Aircraft Operations Center and NOAA Physical } \\
\text { Sciences Laboratory (2020) }\end{array}$ \\
\hline Isotope analyzer water vapor & https://doi.org/10.25921/c5yx-7w29 & National Center for Atmospheric Research (2020) \\
\hline Microphysics & https://doi.org/10.25921/vwvq-5015 & Leandro and Chuang (2020) \\
\hline AXBTs & https://doi.org/10.25921/pe39-sx75 & NOAA Physical Sciences Laboratory (2020a) \\
\hline W-band radar & https://doi.org/10.25921/n1hc-dc30 & NOAA Physical Sciences Laboratory (2020b) \\
\hline Remote sensing & https://doi.org/10.25921/x9q5-9745 & NOAA Physical Sciences Laboratory (2020c) \\
\hline WSRA & https://doi.org/10.25921/qm06-qx04 & Prosensing, Inc. (2020) \\
\hline
\end{tabular}

tained and post-processed data from the WSRA and is the point of contact for data from this instrument. GB assisted with data processing and conversion to NetCDF. RP coordinated data archiving activities and the production of this paper. All authors contributed to the collection and/or processing of the data described.

Competing interests. Author Gijs de Boer is a guest editor for the special issue to which this paper is submitted. The authors declare that they have no other conflict of interest.

Special issue statement. This article is part of the special issue "Elucidating the role of clouds-circulation coupling in climate: datasets from the 2020 (EUREC4A) field campaign". It is not associated with a conference.

Acknowledgements. We are grateful to the pilots, crew, and ground support staff of the WP-3D for their help in obtaining these measurements. The authors thank Tom Boyer and John Relph at NOAA's National Center for Environmental Information for essential help in archiving the data.

Financial support. The ATOMIC field campaign was supported by the NOAA Climate Program Office under the Climate Variability and Predictability Program; collection of data from the P-3 was supported by award GC19-302a. Additional support for processing and collection of ATOMIC WP-3D datasets was provided by the NOAA Physical Sciences Laboratory. Measurements with the isotope analyzer were supported by the National Center for Atmospheric Research, which is a major facility sponsored by the National Science Foundation under cooperative agreement 1852977.

Review statement. This paper was edited by Helene Brogniez and reviewed by two anonymous referees.

\section{References}

Aemisegger, F., Sturm, P., Graf, P., Sodemann, H., Pfahl, S., Knohl, A., and Wernli, H.: Measuring variations of $\delta^{18} \mathrm{O}$ and $\delta^{2} \mathrm{H}$ in atmospheric water vapour using two commercial laser-based spectrometers: an instrument characterisation study, Atmos. Meas. Tech., 5, 1491-1511, https://doi.org/10.5194/amt-5-1491-2012, 2012.

Alappattu, D. P. and Wang, Q.: Correction of Depth Bias in UpperOcean Temperature and Salinity Profiling Measurements from Airborne Expendable Probes, J. Atmos. Ocean. Tech., 32, 247255, https://doi.org/10.1175/JTECH-D-14-00114.1, 2015.

Bane, J. M. and Sessions, M. H.: A Field Performance Test of the Sippican Deep Aircraft-Deployed Expendable Bathythermograph, J. Geophys. Res.-Oceans, 89, 3615-3621, https://doi.org/10.1029/JC089iC03p03615, 1984.

Bony, S. and Stevens, B.: Measuring Area-Averaged Vertical Motions with Dropsondes, J. Atmos. Sci., 76, 767-783, https://doi.org/10.1175/JAS-D-18-0141.1, 2019.

Bony, S., Stevens, B., Ament, F., Bigorre, S., Chazette, P., Crewell, S., Delanoë, J., Emanuel, K., Farrell, D., Flamant, C., Gross, S., Hirsch, L., Karstensen, J., Mayer, B., Nuijens, L., Ruppert, J. H., Sandu, I., Siebesma, P., Speich, S., Szczap, F., Totems, J., Vogel, R., Wendisch, M., and Wirth, M.: EUREC ${ }^{4}$ A: A Field Campaign to Elucidate the Couplings Between Clouds, Convection and Circulation, Surv. Geophys., 38, 1529-1568, https://doi.org/10.1007/s10712-017-9428-0, 2017.

CF (Climate and Forecast) conventions: https://cfconventions.org/, last access: 11 June 2021.

de Boer, G., Borenstein, S., Calmer, R., Cox, C., Rhodes, M., Choate, C., Hamilton, J., Osborn, J., Lawrence, D., Argrow, B., and Intrieri, J.: Measurements from the University of Colorado RAAVEN Uncrewed Aircraft System during ATOMIC, Earth Syst. Sci. Data Discuss. [preprint], https://doi.org/10.5194/essd2021-175, in review, 2021.

Dinegar Boyd, J.: Improved Depth and Temperature Conversion Equations for Sippican AXBTs, J. Atmos. Ocean. Tech., 4, 545-551, https://doi.org/10.1175/15200426(1987)004<0545:IDATCE>2.0.CO;2, 1987. 
EUREC4A Data Portal OpenDAP Access: https://observations.ipsl. fr/thredds/catalog/EUREC4A/catalog.html, last access: 11 June 2021.

Fairall, C. W., Matrosov, S. Y., Williams, C. R., and Walsh, E. J.: Estimation of Rain Rate from Airborne Doppler W-Band Radar in CalWater-2, J. Atmos. Ocean. Tech., 35, 593-608, https://doi.org/10.1175/JTECH-D-17-0025.1, 2018.

George, G., Stevens, B., Bony, S., Pincus, R., Fairall, C., Schulz, H., Kölling, T., Kalen, Q. T., Klingebiel, M., Konow, H., Lundry, A., Prange, M., and Radtke, J.: JOANNE: Joint dropsonde Observations of the Atmosphere in tropical North atlaNtic mesoscale Environments, Earth Syst. Sci. Data Discuss. [preprint], https://doi.org/10.5194/essd-2021-162, in review, 2021.

Hardy, R.: ITS-90 Formulations for Vapor Pressure, Frostpoint Temperature, Dewpoint Temperature, and Enhancement Factors in the Range -100 to $+100 \mathrm{C}$, in: Proceedings of the Third International Symposium on Humidity \& Moisture, Teddington, London, England, April 1998.

Herman, R. L., Worden, J., Noone, D., Henze, D., Bowman, K., Cady-Pereira, K., Payne, V. H., Kulawik, S. S., and Fu, D.: Comparison of optimal estimation $\mathrm{HDO} / \mathrm{H}_{2} \mathrm{O}$ retrievals from AIRS with ORACLES measurements, Atmos. Meas. Tech., 13, 18251834, https://doi.org/10.5194/amt-13-1825-2020, 2020.

Hitschfeld, W. and Bordan, J.: Errors Inherent in the Radar Measurement of Rainfall at Attenuating Wavelengths, J. Meteorol., 11, 58-67, https://doi.org/10.1175/15200469(1954)011<0058:EIITRM>2.0.CO;2, 1954.

Hock, T. F. and Franklin, J. L.: The NCAR GPS Dropwindsonde, B. Am. Meteorol. Soc., 80, 407-420, https://doi.org/10.1175/15200477(1999)080<0407:TNGD>2.0.CO;2, 1999.

Iguchi, T. and Meneghini, R.: Intercomparison of SingleFrequency Methods for Retrieving a Vertical Rain Profile from Airborne or Spaceborne Radar Data, J. Atmos. Ocean. Tech., 11, 1507-1516, https://doi.org/10.1175/15200426(1994)011<1507:IOSFMF>2.0.CO;2, 1994.

ITU-R: Attenutation by Atmospheric Gases, Recommendation ITU-R P.676-10, International Telecommunications Union (ITU), Geneva, 2013.

Leandro, M. and Chuang, P.: ATOMIC aircraft in situ microphysics: Size-resolved cloud and aerosol number concentrations taken from N43 aircraft in the North Atlantic Ocean, Barbados: Atlantic Tradewind Ocean-Atmosphere Mesoscale Interaction Campaign 2020-01-31 to 2020-02-10 (NCEI Accession 0232458), NOAA National Centers for Environmental Information [data set], https://doi.org/10.25921/vwvq-5015, 2020.

Lenschow, D. H., Savic-Jovcic, V., and Stevens, B.: Divergence and Vorticity from Aircraft Air Motion Measurements, J. Atmos. Ocean. Tech., 24, 2062-2072, https://doi.org/10.1175/2007JTECHA940.1, 2007.

Li, L., Heymsfield, G. M., Tian, L., and Racette, P. E.: Measurements of Ocean Surface Backscattering Using an Airborne 94GHz Cloud Radar - Implication for Calibration of Airborne and Spaceborne W-Band Radars, J. Atmos. Ocean. Tech., 22, 10331045, https://doi.org/10.1175/JTECH1722.1, 2005.

Moran, K., Pezoa, S., Fairall, C. W., Williams, C., Ayers, T., Brewer, A., de Szoeke, S. P., and Ghate, V.: A MotionStabilized W-Band Radar for Shipboard Observations of Marine Boundary-Layer Clouds, Bound.-Lay. Meteorol., 143, 3-24, https://doi.org/10.1007/s10546-011-9674-5, 2012.
National Center for Atmospheric Research: ATOMIC aircraft water vapor Picarro: Water vapor measurements from isotope analyzer aboard N43 aircraft in the North Atlantic Ocean, Barbados: Atlantic Tradewind Ocean-Atmosphere Mesoscale Interaction Campaign 2020-01-17 to 2020-02-11 (NCEI Accession 0220631), NOAA National Centers for Environmental Information [data set], https://doi.org/10.25921/c5yx-7w29, 2020.

NOAA Aircraft Operations Center and NOAA Physical Sciences Laboratory: ATOMIC Aircraft Flight Level Navigation Meteorology: Wind Speed, Relative Humidity, Aircraft Parameters, and Other Measurements Taken from N43 Aircraft in the North Atlantic Ocean, Barbados: Atlantic Tradewind Ocean-Atmosphere Mesoscale Interaction Campaign 2020-01-17 to 2020-02-11 (NCEI Accession 0220621), NOAA National Centers for Environmental Information [data set], https://doi.org/10.25921/7jf5wv54, 2020.

NOAA Physical Sciences Laboratory: ATOMIC aircraft AXBT: Subsurface ocean temperature measurements from Airborne eXpendable BathyThermographs (AXBT) deployed from N43 aircraft, Barbados: Atlantic Tradewind Ocean-Atmosphere Mesoscale Interaction Campaign 2020-01-19 to 2020-02-11 (NCEI Accession 0220436), NOAA National Centers for Environmental Information [data set], https://doi.org/10.25921/pe39sx75, 2020a.

NOAA Physical Sciences Laboratory: ATOMIC aircraft remote sensing cloud, rain, wind, wave: Cloud and precipitation parameters and 10-meter wind speed estimated from remote sensing instruments aboard N43 aircraft in the North Atlantic Ocean, Barbados: Atlantic Tradewind Ocean-Atmosphere Mesoscale Interaction Campaign 2020-01-17 to 2020-02-11 (NCEI Accession 0220625), NOAA National Centers for Environmental Information [data set], https://doi.org/10.25921/x9q5-9745, $2020 \mathrm{~b}$.

NOAA Physical Sciences Laboratory: ATOMIC aircraft W-band radar: Reflectivity, Doppler velocity, and spectral width taken from W-band radar abouard N43 aircraft in the North Atlantic Ocean, Barbados: Atlantic Tradewind Ocean-Atmosphere Mesoscale Interaction Campaign 2020-01-17 to 2020-02-11 (NCEI Accession 0220624), NOAA National Centers for Environmental Information [data set], https://doi.org/10.25921/n1hcdc30, 2020c.

PopStefanija, I., Fairall, C. W., and Walsh, E. J.: Mapping of Directional Ocean Wave Spectra in Hurricanes and Other Environments, IEEE T. Geosci. Remote, Sensing, 1-14, https://doi.org/10.1109/TGRS.2020.3042904, 2020.

Prosensing, Inc.: ATOMIC aircraft remote sensing wave, rain:Wave height and other measurements from wide-swath radar altimeter (WSRA) aboard N43 aircraft in the North Atlantic Ocean, Barbados: Atlantic Tradewind Ocean-Atmosphere Mesoscale Interaction Campaign 2020-01-17 to 2020-02-11 (NCEI Accession 0220627), NOAA National Centers for Environmental Information [data set], https://doi.org/10.25921/qm06-qx04, 2020.

Quinn, P. K., Thompson, E. J., Coffman, D. J., Baidar, S., Bariteau, L., Bates, T. S., Bigorre, S., Brewer, A., de Boer, G., de Szoeke, S. P., Drushka, K., Foltz, G. R., Intrieri, J., Iyer, S., Fairall, C. W., Gaston, C. J., Jansen, F., Johnson, J. E., Krüger, O. O., Marchbanks, R. D., Moran, K. P., Noone, D., Pezoa, S., Pincus, R., Plueddemann, A. J., Pöhlker, M. L., Pöschl, U., Quinones Melendez, E., Royer, H. M., Szczodrak, M., Thomson, J., Upchurch, L. M., Zhang, C., Zhang, D., and Zuidema, P.: Measurements 
from the RV Ronald H. Brown and related platforms as part of the Atlantic Tradewind Ocean-Atmosphere Mesoscale Interaction Campaign (ATOMIC), Earth Syst. Sci. Data, 13, 1759-1790, https://doi.org/10.5194/essd-13-1759-2021, 2021.

Sapp, J., Alsweiss, S., Jelenak, Z., Chang, P., and Carswell, J.: Stepped Frequency Microwave Radiometer WindSpeed Retrieval Improvements, Remote Sens., 11, 214, https://doi.org/10.3390/rs11030214, 2019.

Sodemann, H., Aemisegger, F., Pfahl, S., Bitter, M., Corsmeier, U., Feuerle, T., Graf, P., Hankers, R., Hsiao, G., Schulz, H., Wieser, A., and Wernli, H.: The stable isotopic composition of water vapour above Corsica during the HyMeX SOP1 campaign: insight into vertical mixing processes from lowertropospheric survey flights, Atmos. Chem. Phys., 17, 6125-6151, https://doi.org/10.5194/acp-17-6125-2017, 2017.

Stephan, C. C., Schnitt, S., Schulz, H., Bellenger, H., de Szoeke, S. P., Acquistapace, C., Baier, K., Dauhut, T., Laxenaire, R., Morfa-Avalos, Y., Person, R., Quiñones Meléndez, E., Bagheri, G., Böck, T., Daley, A., Güttler, J., Helfer, K. C., Los, S. A., Neuberger, A., Röttenbacher, J., Raeke, A., Ringel, M., Ritschel, M., Sadoulet, P., Schirmacher, I., Stolla, M. K., Wright, E., Charpentier, B., Doerenbecher, A., Wilson, R., Jansen, F., Kinne, S., Reverdin, G., Speich, S., Bony, S., and Stevens, B.: Shipand island-based atmospheric soundings from the 2020 EUREC4A field campaign, Earth Syst. Sci. Data, 13, 491-514, https://doi.org/10.5194/essd-13-491-2021, 2021.

Stevens, B., Bony, S., Farrell, D., Ament, F., Blyth, A., Fairall, C., Karstensen, J., Quinn, P. K., Speich, S., Acquistapace, C., Aemisegger, F., Albright, A. L., Bellenger, H., Bodenschatz, E., Caesar, K.-A., Chewitt-Lucas, R., de Boer, G., Delanoë, J., Denby, L., Ewald, F., Fildier, B., Forde, M., George, G., Gross, S., Hagen, M., Hausold, A., Heywood, K. J., Hirsch, L., Jacob, M., Jansen, F., Kinne, S., Klocke, D., Kölling, T., Konow, H., Lothon, M., Mohr, W., Naumann, A. K., Nuijens, L., Olivier, L., Pincus, R., Pöhlker, M., Reverdin, G., Roberts, G., Schnitt, S., Schulz, H., Siebesma, A. P., Stephan, C. C., Sullivan, P., Touzé-Peiffer, L., Vial, J., Vogel, R., Zuidema, P., Alexander, N., Alves, L., Arixi, S., Asmath, H., Bagheri, G., Baier, K., Bailey, A., Baranowski, D., Baron, A., Barrau, S., Barrett, P. A., Batier, F., Behrendt, A., Bendinger, A., Beucher, F., Bigorre, S., Blades, E., Blossey, P., Bock, O., Böing, S., Bosser, P., Bourras, D., Bouruet-Aubertot, P., Bower, K., Branellec, P., Branger, H., Brennek, M., Brewer, A., Brilouet, P.-E., Brügmann, B., Buehler, S. A., Burke, E., Burton, R., Calmer, R., Canonici, J.-C., Carton, X., Cato Jr., G., Charles, J. A., Chazette, P., Chen, Y., Chilinski, M. T., Choularton, T., Chuang, P., Clarke, S., Coe, H., Cornet, C., Coutris, P., Couvreux, F., Crewell, S., Cronin, T., Cui, Z., Cuypers, Y., Daley, A., Damerell, G. M., Dauhut, T., Deneke, H., Desbios, J.-P., Dörner, S., Donner, S., Douet, V., Drushka, K., Dütsch, M., Ehrlich, A., Emanuel, K., Emmanouilidis, A., Etienne, J.-C., Etienne-Leblanc, S., Faure, G., Feingold, G., Ferrero, L., Fix, A., Flamant, C., Flatau, P. J., Foltz, G. R., Forster, L., Furtuna, I., Gadian, A., Galewsky, J., Gallagher, M., Gallimore, P., Gaston, C., Gentemann, C., Geyskens, N., Giez, A., Gollop, J., Gouirand, I., Gourbeyre, C., de Graaf, D., de Groot, G. E., Grosz, R., Güttler, J., Gutleben, M., Hall, K., Harris, G., Helfer, K. C., Henze, D., Herbert, C., Holanda, B., Ibanez-Landeta, A., Intrieri, J., Iyer, S., Julien, F., Kalesse, H., Kazil, J., Kellman, A., Kidane, A. T., Kirchner, U., Klingebiel, M., Körner, M., Krem- per, L. A., Kretzschmar, J., Krüger, O., Kumala, W., Kurz, A., L'Hégaret, P., Labaste, M., Lachlan-Cope, T., Laing, A., Landschützer, P., Lang, T., Lange, D., Lange, I., Laplace, C., Lavik, G., Laxenaire, R., Le Bihan, C., Leandro, M., Lefevre, N., Lena, M., Lenschow, D., Li, Q., Lloyd, G., Los, S., Losi, N., Lovell, O., Luneau, C., Makuch, P., Malinowski, S., Manta, G., Marinou, E., Marsden, N., Masson, S., Maury, N., Mayer, B., MayersAls, M., Mazel, C., McGeary, W., McWilliams, J. C., Mech, M., Mehlmann, M., Meroni, A. N., Mieslinger, T., Minikin, A., Minnett, P., Möller, G., Morfa Avalos, Y., Muller, C., Musat, I., Napoli, A., Neuberger, A., Noisel, C., Noone, D., Nordsiek, F., Nowak, J. L., Oswald, L., Parker, D. J., Peck, C., Person, R., Philippi, M., Plueddemann, A., Pöhlker, C., Pörtge, V., Pöschl, U., Pologne, L., Posyniak, M., Prange, M., Quiñones Meléndez, E., Radtke, J., Ramage, K., Reimann, J., Renault, L., Reus, K., Reyes, A., Ribbe, J., Ringel, M., Ritschel, M., Rocha, C. B., Rochetin, N., Röttenbacher, J., Rollo, C., Royer, H., Sadoulet, P., Saffin, L., Sandiford, S., Sandu, I., Schäfer, M., Schemann, V., Schirmacher, I., Schlenczek, O., Schmidt, J., Schröder, M., Schwarzenboeck, A., Sealy, A., Senff, C. J., Serikov, I., Shohan, S., Siddle, E., Smirnov, A., Späth, F., Spooner, B., Stolla, M. K., Szkółka, W., de Szoeke, S. P., Tarot, S., Tetoni, E., Thompson, E., Thomson, J., Tomassini, L., Totems, J., Ubele, A. A., Villiger, L., von Arx, J., Wagner, T., Walther, A., Webber, B., Wendisch, M., Whitehall, S., Wiltshire, A., Wing, A. A., Wirth, M., Wiskandt, J., Wolf, K., Worbes, L., Wright, E., Wulfmeyer, V., Young, S., Zhang, C., Zhang, D., Ziemen, F., Zinner, T., and Zöger, M.: EUREC4A, Earth Syst. Sci. Data Discuss. [preprint], https://doi.org/10.5194/essd-2021-18, in review, 2021.

Thomson, J.: Wave Breaking Dissipation Observed with "SWIFT" Drifters, J. Atmos. Ocean. Tech., 29, 1866-1882, https://doi.org/10.1175/JTECH-D-12-00018.1, 2012.

Uhlhorn, E. W., Black, P. G., Franklin, J. L., Goodberlet, M., Carswell, J., and Goldstein, A. S.: Hurricane Surface Wind Measurements from an Operational Stepped Frequency Microwave Radiometer, Mon. Weather Rev., 135, 3070-3085, https://doi.org/10.1175/MWR3454.1, 2007.

Walsh, E. J., Vandemark, D. C., Friehe, C. A., Burns, S. P., Khelif, D., Swift, R. N., and Scott, J. F.: Measuring Sea Surface Mean Square Slope with a 36-GHz Scanning Radar Altimeter, J. Geophys. Res., 103, 12587-12601, https://doi.org/10.1029/97JC02443, 1998.

Walsh, E. J., PopStefanija, I., Matrosov, S. Y., Zhang, J., Uhlhorn, E., and Klotz, B.: Airborne Rain-Rate Measurement with a WideSwath Radar Altimeter, J. Atmos. Ocean. Tech., 31, 860-875, https://doi.org/10.1175/JTECH-D-13-00111.1, 2014. 